\title{
Aristocracias chané. « Casas » en el Chaco argentino y boliviano
}

Isabelle Combès y Diego Villar

\section{(2) OpenEdition}

\section{Journals}

Edición electrónica

URL: https://journals.openedition.org/jsa/1664

DOI: $10.4000 /$ jsa. 1664

ISSN: 1957-7842

Editor

Société des américanistes

\section{Edición impresa}

Fecha de publicación: 5 junio 2004

Paginación: 63-102

ISSN: 0037-9174

\section{Referencia electrónica}

Isabelle Combès y Diego Villar, «Aristocracias chané. "Casas » en el Chaco argentino y boliviano», Journal de la Société des américanistes [En línea], 90-2 | 2004, Publicado el 05 junio 2009, consultado el 03 septiembre 2022. URL: http://journals.openedition.org/jsa/1664 ; DOl: https://doi.org/10.4000/jsa. 1664 


\title{
ARISTOCRACIAS CHANÉ. « CASAS » EN EL CHACO ARGENTINO Y BOLIVIANO
}

\author{
Isabelle COMBÈS * y Diego VILLAR ** 1 \\ "Entre los chiriguano y los chané, las familias de los jefes \\ forman una especie de aristocracia. »
}

(Nordenskiöld 2002 [1912])

" El bastón de mando no debe salir de la casa-digamosreal. »

(Giannecchini 1996 [1898])

\begin{abstract}
Donde la lectura canónica del cacicazgo chané ha visto jefes sin poderes y asambleas democráticas, los datos etnográficos e históricos muestran, por el contrario, poderosas dinastías de dirigentes y jefaturas hereditarias. Después de presentar dos estudios de caso, los chané del noroeste argentino y los izoceños de Bolivia, se propone la utilización del concepto de "Casa », desarrollado por Lévi-Strauss, para una aprehensión cabal del sistema político chané. Se evidencia que el tradicional modelo explicativo del cacicazgo chané procede de una visión « guaranizante » que sin más no puede aplicarse a la realidad concreta. Las líneas finales se interrogan sobre el futuro de las Casas chané en los tiempos más "democráticos » que proponen hoy los movimientos indígenas. [PALABRAS ClAves : jefatura, etnohistoria, organización sociopolítica, Casa, chané, guaraní, chiriguano, Chaco.]
\end{abstract}

Chané aristocracies. "Houses » in the Argentinian and Bolivian Chaco. While the classic views of chané leadership posits powerless leaders and democratic assemblies, ethnographical and ethnohistorical data suggest to the contrary quite powerful and hereditary dynasties. After presenting two case-studies, the Chané of northwestern Argentina and the Bolivian Izoceños, the application of the concept of « House »- as developed by Lévi-Strauss - is proposed in order to explain the Chané political system. It is argued that the traditional account of the leadership is mainly a « Guaranized » one, which can not fully explain the Chane facts. The final section deals with the future of the Chané Houses in the more " democratic » times impulsed by contemporary indigenous movements. [KEY wORDS : leadership, ethnohistory, sociopolitical organization, House, Chané, Guaraní, Chiiguano, Chaco.]

* Instituto Francés de Estudios Andinos (IFEA), Santa Cruz, Bolivia [isabelle@unete.com].

** Consejo Nacional de Investigaciones Cientificas y Técnicas (CONICET), Buenos Aires, Argentine [dvillar@fullzero.com.ar].

Journal de la Société des Américanistes, 2004, 90-2, pp. 63-102. CS Société des Américanistes. 
Aristocraties chané. "Maisons » dans le Chaco argentin et bolivien. Là où la lecture canonique de la chefferie chané a vu des " capitaines » sans pouvoir et des assemblées démocratiques, les données ethnographiques et historiques révèlent, au contraire, de puissantes dynasties de dirigeants et des chefferies héréditaires. Deux études de cas, les Chané du Nord-Ouest argentin et les Izoceños de Bolivie, sont d'abord présentées. On propose ensuite l'utilisation du concept de "Maison », développé par Lévi-Strauss, pour une plus juste appréhension du système politique chané. L'analyse montre que le modèle explicatif traditionnel de la chefferie chané procède d'une vision "guaranisante » qui ne peut être appliquée telle quelle à la réalité concrète. On s'interroge finalement sur le futur des Maisons chané en ces temps plus " démocratiques » que proposent aujourd'hui les mouvements indiens. [Mots CLÉs : chefferie, ethnohistoire, organisation sociopolitique, Maison, Chané, Guarani, Chiriguano, Chaco.]

\section{INTRODUCCION}

Pierre Clastres (1974, p. 26 trad. nuestra) escribió que « la mayoría de las sociedades amerindias se distinguen, en lo esencial, por su sentido de la democracia y su gusto por la igualdad ». Hay muy pocas excepciones, según Clastres : los guaycurú y los guana del Gran Chaco. Simbiótica y jerárquica, su estructura constituye un ejemplo célebre en la antropología chaqueña : los mbayá (guaycurú) tenían el dominio político y la jerarquía social más baja correspondía a sus siervos guana (arawak). En el Chaco también, pero más hacia el oeste, el mismo esquema se repite, aunque esta vez entre dominadores guaraní y siervos chané, también de origen arawak. Los guaraní y los chané se mestizaron en el pie de monte andino y en el Chaco boreal, constituyendo la etnia conocida como " chiriguano » : una sociedad mestiza pero, también, asimétrica y jerárquica, en la cual el elemento guaraní subordinó al chané (Combès y Saignes 1991). Una sociedad, en suma, tan poco « clastreana » como la guaycurú.

Sin embargo, el modelo propuesto por Clastres, o más generalmente y sin referencia explícita a este autor, el modelo de una sociedad igualitaria, sigue siendo utilizado con frecuencia para describir a las sociedades de los chané y chiriguano. La literatura etnográfica chaqueña ha trazado una imagen canónica de la jefatura cacical entre los chiriguano que a menudo también es aplicada - sin mucho discernimiento y sin prestar atención a las diferencias culturales e históricas entre ambos pueblos - a los chané. Este modelo canónico se apoya sobre testimonios coloniales ; sobre clásicos venerables como las obras de los misioneros franciscanos del siglo XIX ; las investigaciones de pioneros de la etnología chaqueña como Nordenskiöld (2002), Métraux (1948) o Susnik (1968) ; y también sobre las de autores más modernos, como Braunstein (1983) o Hirsch (1991).

Dador de convites, forjador de alianzas por medio de matrimonios poligínicos y explotador al máximo de las relaciones avunculares, el jefe chiriguano se ha erigido en un estereotipo chaqueño : tradicionalmente distinguido por su coraje, 
su saber y su elocuencia, podía aspirar a ser un " gran hombre », un kereimba (guerrero), un ñee iya (dueño de las palabras) o un arakua iya (dueño de la sabiduría). Sus principales funciones consistían en calmar los roces internos, administrar justicia, coordinar la celebración de las fiestas y fundamentalmente en comandar la guerra. A veces era asistido por un consejo de chamanes y ancianos eminentes. Pero en todos los casos se subraya que el pueblo tomaba sus propias decisiones a través de la asamblea. El cacique debía ganar respeto predicando con el ejemplo, pues carecía de coerción ; de allí, la importancia decisiva del don de la oratoria. El líder - mburuvicha o " capitán » - debía ser además una persona generosa, que contara con una sólida red de parentesco y alianzas, que le permitiese ofrecer ayuda militar e invitaciones para los frecuentes convites de chicha.

El capitán chiriguano ha sido representado, en definitiva, como un « jefe sin poder ». A la vez, parafraseando a Clastres, la asamblea parece ser la « sede » del poder. De hecho, la organización política de los chiriguano de Bolivia es la Asamblea del Pueblo Guaraní. Si bien no se pretende que los algo más de 60000 chiriguano lleguen a participar directamente de la misma, sí se supone que lo pueden hacer mediante sus representantes, elegidos democráticamente en cada comunidad. Más clastreano que su propio inspirador, Thierry Saignes (1990) fue quien más recurrió a « la sociedad contra el Estado » para explicar la historia y la política chiriguano. La historia del pueblo chiriguano, nos dice, es una " guerra contra la historia » (Saignes 1985) o, en otras palabras, contra el Estado. Este modelo consagrado no parece forzosamente erróneo, pero sí parcial. Sin refutarlo, aquí procuraremos matizarlo y acaso enriquecerlo destacando dimensiones analíticas tal vez menos conocidas pero igualmente fundamentales en la realidad cotidiana de los izoceños y los chané.

La lectura tradicional de la jefatura chiriguana peca, al menos, en tres sentidos. Primero, suele incurrir en el prejuicio - crónico - de considerar a los chané y a los diferentes grupos chiriguano (ava y simba) como si fueran grupos exactamente iguales, ignorando desarrollos históricos locales y singularidades étnicas que no dejan de existir por el mero hecho de compartir una lengua. Pues, si bien la inmensa mayoría de los chané fue "absorbida » en la nueva etnia mestiza chiriguana durante los siglos coloniales, debe recalcarse que algunos grupos chané conformaron núcleos independientes los cuales, aunque « guaranizados » en particular en el plano lingüístico, siguieron llamándose chané. Estos núcleos fueron los del río Acero y de Kaipependi del Pilcomayo en el siglo XVIII, hoy desaparecidos o « mimetizados » en la población criolla ; los del Izozog (los izoceños son llamados "chané del Parapetí » incluso hasta Nordenskiöld) así como del Itiyuro en el norte argentino (éste último grupo tal vez conformado a finales del siglo XVIII), y de ellos vamos a hablar en estas páginas. Izoceños, chané argentinos, ava y simba son conscientes todos de sus respectivas similitudes, pero también de sus diferencias, lo cual hace que se conciben en todos los casos como 
distintos los unos de los otros; de hecho, los problemas internos de la Asamblea del Pueblo Guaraní en Bolivia no tienen otro origen.

En segundo lugar, el modelo ortodoxo se basa sobre una descripción fundamentalmente chiriguana, y más que chiriguana sobre una descripción guaraní. Se sabe que los chiriguano son una etnia mixta, y que los chané han desempeñado un papel importante en su conformación (Susnik 1968 ; Braunstein 1983 ; Combès y Saignes 1991). Pero, por lo general, la atención de los estudiosos se ha limitado a comprobar qué efectos tuvo la llamada "guaranización 》 de los chané, sin reflejar la (simultánea) « arawakanización » de los guaraní. Aquí intentaremos, en consonancia con otros trabajos recientes que proponen una rehabilitación del legado chané-arawak (Combès y Lowrey 2004), rastrear precisamente este influjo en un fenómeno concreto ; es decir, identificar características que nos permitan singularizar la jefatura chané dentro del (mal) llamado « complejo chiriguanochané ».

Por último, la idea de los chiriguano o chané como sociedades « contra el Estado » descansa, por así decirlo, sobre una macrovisión que enfoca su mirada sobre una totalidad étnica denominada « nación » o « pueblo » chiriguano. Pero, aunque parezca una ironía histórica, es un hecho incontrastable que este " pueblo » jamás tuvo un liderazgo centralizado y único hasta la creación, en 1987, de la Asamblea del Pueblo Guaraní. En un nivel de observación menos abarcativo, y si se acepta desentrañar la madeja de relaciones que constituye cada « capitanía " particular, la imagen tradicional se desdibuja visiblemente.

Comenzaremos retomando las observaciones pioneras de Nordenskiöld, en 1908, un aporte excepcional para nuestro conocimiento del cacicazgo chané. El sueco otorga una consistencia mucho más marcada a un factor que sólo había sido sugerido con timidez por los misioneros franciscanos. Nino (1912, p. 165) ciertamente había anotado que el mburuvicha era sucedido por su hijo mayor; y Giannecchini (1996, p. 302) calificado el cacicazgo como «monárquico y hereditario ». No obstante, los énfasis de ambos observadores vuelven rápidamente a la asamblea, la posibilidad de remoción del cacique, la toma comunitaria de decisiones y el consejo de ancianos ; en suma, a diluir la autoridad cacical en una multitud de poderes parciales. Donde la lectura tradicional describe un cacicazgo hereditario pero removible, Nordenskiöld sospecha en cambio un cacicazgo removible pero hereditario.

Entre los chané argentinos, Nordenskiöld (2002, p. 157) relata que su principal informante fue Vocapoy, "jefe» y "regente » por enfermedad de su tía Vuayrúyi ; en el Izozog, fue Batirayu, quien se presenta como « sobrino del gran jefe Aringuis ». A esta proliferación de títulos rimbombantes el sueco añade una preocupación explícita por el atesoramiento de genealogías : Batirayu recuerda que antes de su tío Aringuis estaba Yambáe, que antes de éste estaba Ochoápi y antes, Chótchori. A diferencia de los otros grupos chaqueños, anota Nordenskiöld (ibid., p. 212), «entre los chiriguano y los chané las familias de los jefes 
forman una especie de aristocracia » (énfasis nuestro). Estos « brotes de nobleza » se evidencian no sólo en el poder efectivo de los big men, sino en su capacidad oratoria, su influencia en ámbitos supracomunitarios y, sobre todo, en la tenaz recurrencia a la legitimación histórica mediante genealogías. Concluye Nordenskiöld (ibid., pp. 211-213) que los chané no sólo recuerdan, sino que reivindican de forma llamativa, ciertas líneas elitescas de continuidad, a las cuales no duda en calificar de « linajes ».

Todo indica que existe un profundo desfase entre la lectura canónica de la jefatura chiriguano y chané y sus realidades históricas. Consciente de ello, sin embargo, un autor como Saignes (1990, p. 12) nunca se apartó de su modelo, y llegó a calificar al sistema chiriguano como « un sistema político igualitario con valores que no lo son " ; frase un tanto enigmática - y muchas veces repetida que, confesamos, nos deja perplejos.

Otros autores sí han captado las jerarquías y estratificaciones sociales : es el caso de Susnik (1968), de Braunstein (1983) y, más recientemente, de una de nosotros (Combès y Lowrey 2004). Todos estos trabajos coinciden sobre un punto clave. Al igual que la jerarquía « externa » entre guaraní y chané que funda a la sociedad de los chiriguano, su jerarquía " interna » entre " aristocracias » y commoners tiene, muy probablemente, un origen arawak. Es más, la una pudo servir de modelo para la otra. Los guaraní acaso ocuparon los puestos más altos de la jerarquía chané para dominarlos mejor, en un proceso gemelo al que tuvo lugar entre los mbayá y los guana. Existen, ciertamente, antecedentes de la estratificación sociopolítica chané en el Paraguay colonial (Susnik 1983, pp. 125126). Las palabras de Sánchez Labrador (cit. por Susnik 1971, p. 145), a finales del siglo XviII, parecen inequívocas :

Están los Chanas divididos en capitanías. Las principales son las de los caciques que son como régulos de los demás. Los capitanes menores recaen en los parientes de los caciques, y así éstos como los caciques menores procuran continuar la mística nobleza de su sangre casándose entre sí, los de igual jerarquía por no envilecerse con la plebe. (énfasis nuestro)

La tesis de un origen arawak de este modelo estratificado encuentra respaldo comparativo en otros casos, desarrollados en particular por Hornborg (1988, pp. 127, 276-284) y Combès y Lowrey (2004). Estos mismos rasgos fueron incluidos por Santos Granero (2002) en su reciente propuesta de lo que llamó un " ethos arawak ». Mencionamos la tendencia arawak a la jerarquía, la estratificación y la endogamia de rango, y la mencionamos obligatoriamente, porque nuestros propios estudios de caso en capitanías chané (aunque estén a menudo identificadas como « chiriguano ») bien pueden servirle como ilustración.

Sin embargo, más allá de las conjeturas sobre el origen de esta organización estratificada y de sus probables raíces históricas, nos interesa destacar la dinámica de su funcionamiento concreto en dos grupos chané contemporáneos. Empeza- 
remos presentando los dos estudios de caso, identificando los paralelos y las diferencias entre ambos. Para ello buscaremos un modelo explicativo que nos permita integrar los datos recogidos. Esta noción, que utilizaremos aquí como herramienta « buena para pensar », no es nueva, y pertenece ya al arsenal clásico de la antropología : se trata del concepto de " Casa », tal como fuera desarrollado por Lévi-Strauss (1984, 1987 y 1996). Otros autores, en particular Hugh-Jones (1993) o Carsten y Hugh-Jones (1995), recurrieron al mismo para explicar realidades « mixtas », « ambiguas » $\mathrm{o}$ « mezcladas » desde el punto de vista de las categorías antropológicas clásicas. Pero nuestro estudio enfatiza, más bien, aquel aspecto político de la Casa - la maison noble - sobre el cual originalmente insistió Lévi-Strauss. Queremos también prestar especial atención a la proliferación contemporánea de nuevas formas de poder, como la aparición de los llamados caciques " lenguaraces », las " nuevas élites » compuestas por indígenas que se han volcado hacia el trabajo con las ONG, las municipalidades, las iglesias, las agencias de desarrollo, etc. Algunas veces las élites « tradicionales » se superponen con las « modernas »; pero otras no, y en tal caso es preciso desentrañar las relaciones entre ambas. Lejos de ignorar o soslayar las tensiones, asimetrías y conflictos que oponen a las « aristocracias » con la gente común, nuestra propuesta propone una lectura que refleja no sólo los principios estructurales en conflicto o utilizados estratégicamente por los actores, sino también clivajes y divisiones que van mucho más allá de la clásica oposición clastreana entre jefes « centrípetos » y chamanes « centrífugos ».

\section{ARISTOCRACIAS CHANÉ}

A menudo incluidos en el « complejo » o « civilización » chiriguano, tanto los izoceños bolivianos como los chané del noroeste argentino (Figura 1) perciben y defienden, sin embargo, su diferencia. Aunque estén " guaranizados » lingüística y en buena medida culturalmente, los chané argentinos no se consideran " guaraní ». En Bolivia, donde - en gran parte bajo la influencia de los recientes movimientos indigenistas - los izoceños sí se consideran miembros del « pueblo guaraní », conservan sin embargo el nombre de tapi, que no es otro que el nombre dado por los chiriguano de antaño a sus esclavos chané. Sea por su idioma, cuyas peculiaridades pueden ser resultado de su herencia arawak, o por ciertos aspectos de la cultura material como las técnicas de riego o las máscaras, los izoceños siguen siendo aquellos "chané del bajo Parapetí » que visitó Nordenskiöld (2002) a inicios del siglo Xx. Aun siendo miembros de la Asamblea del Pueblo Guaraní, establecen, como los chané del noroeste argentino, una clara diferencia entre ellos y los chiriguano ava o simba.

El hecho de compartir y mantener viva una misma herencia chané no impide, sin embargo, que existan diferencias entre los dos grupos. Los izoceños son 


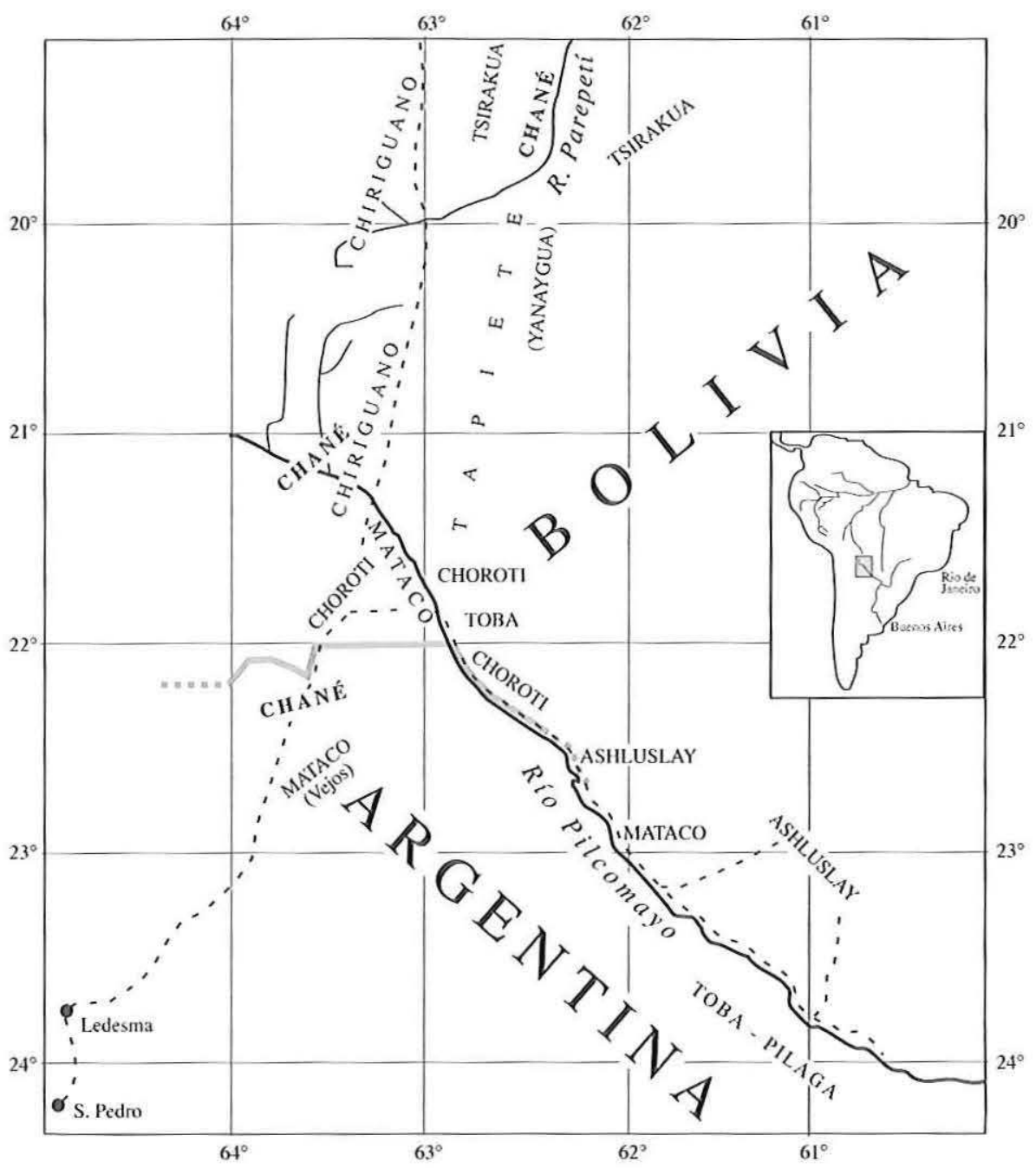

F1G. 1 - Ubicación de los chané argentinos y de los izoceños de Bolivia (reproducida a partir de una carta en Nordenskiöld 2002). 
actualmente unos 9000 individuos repartidos en veinticinco comunidades; los chané argentinos alcanzan apenas a unas 1500 personas, distribuidas en cuatro comunidades relativamente pequeñas. Mediante capitanías locales, « capitanías grandes " $\mathrm{y}$ - en un nivel superior - la Asamblea del Pueblo Guaraní, los izoceños están organizados en formas regionales de asociación ; lo cual no se aplica - o ya no se aplica - en el caso de los chané argentinos. La historia reciente de ambos grupos, miembros de dos países distintos, tampoco es completamente comparable ; esta historia es, además, mucho más conocida en el caso boliviano que en el argentino. Este hecho, sumado a las especialidades diferentes de los autores de estas líneas, explica por qué el tratamiento del caso izoceño seguirá una línea más netamente etnohistórica que la descripción del caso chané, más etnográfica y sincrónica.

Con todo, los paralelos parecen más significativos que las eventuales diferencias; de hecho, son los que nos permitirán hablar aquí, como de un mismo fenómeno, de lo que llamamos « Casas » chané. Más aún, el hecho de arribar a conclusiones generalizables pese a que hayamos partido de "muestras » de distintas escalas poblacionales, demográficas e históricas, y de que sus respectivos tratamientos analíticos hayan sido diferentes, legitima de manera particular, según creemos, las hipótesis aquí expuestas.

\section{Los chané del noroeste argentino}

En el noroeste argentino, no pocas observaciones de Nordenskiöld pueden constatarse, aun en la actualidad. Los habitantes de Tuyunti, la comunidad chané más numerosa de Argentina, esgrimen todavía hoy una genealogía en forma de linaje que presenta a su cacique como descendiente directo, tras siete generaciones, del mismo Cochou o Kotchoy mencionado por el sueco, padre del Vocapoy que le servía como informante y que le presentó, a su vez, su propia genealogía (Nordenskiöld 2002, p. 212). El cacique actual de Tuyunti se llama Vicente Centeno, o Taparindu en guaraní. Él y su familia se jactan de su larga dinastía de capitanes. El cargo se hereda por línea agnática y, preferentemente, a los hijos mayores. Según recuerdan, el primero de ellos fue Cochou, a quienes siguieron Mocapoy o Vocapoya, luego Tabariti, Chukuri, Tupare, Acharei, Mayari y, finalmente, Taparindu. La importancia de esta construcción recibe una reivindicación explícita en la idea de que Tuyunti es la « capital » del territorio chané : " la tierra del caciquismo ». Esta capacidad de remontar las relaciones de parentesco hasta alrededor de 1850 es excepcional, y de ningún modo puede ser atribuida a todos los chané. Su mantenimiento es ciertamente un privilegio, pero también un deber.

En el pasado, el linaje cacical no fue únicamente una cuna de grandes guerreros, sino también una especie de garante de la endogamia étnica. Si bien entre los chané la tasa de matrimonios interétnicos parece irrisoria cuando es comparada con la de los grupos vecinos, en la visión de los informantes el actual 
estado de cosas, en el que hay demasiados matrimonios « entreverados » o " cruzados », es causa directa de la declinación del poder cacical. En el pasado, los caciques vigilaban que nadie ingresara al territorio chané. Con el mismo argumento se explican las victorias militares sobre los chiriguano que invadían sus tierras desde Bolivia : antes tenían « caciques en serio ».

Parece poco probable que la idea nativa de «línea hereditaria » refleje de forma totalmente objetiva los procesos concretos de transmisión o herencia. Los hechos parecen ser un poco más intrincados. Si bien es cierto que, en el ámbito de estas familias cacicales, se heredan - de hecho, para el chané común, estos mismos verbos no tienen demasiado sentido - determinados cargos, bienes, privilegios y responsabilidades, también lo es que esto no siempre ocurre siguiendo a rajatabla los criterios de la agnación y el mayorazgo. Se constata una serie de mecanismos más complejos, que delatan una intención consciente de continuidad, pero que sigue una "línea » algo más sinuosa. En efecto, la afiliación al linaje cacical admitió ocasionalmente desvios por el lado materno, ramificaciones debidas al peso de la uxorilocalidad en la conformación cotidiana de las familias extensas, las inexorables eventualidades de muertes tempranas, descendencias truncas e incluso hijos que - por razones diversas - no pudieron o quisieron asumir el cargo. Sea acertado o no el trazado genealógico del linaje, sea « real » o "clasificatoria » la forma de afiliación que plantea, lo importante es que su misma existencia revela una manera bien concreta mediante la cual la sociedad chané ha querido concebir su propia continuidad.

No acaba aquí el papel desempeñado por las familias cacicales en el mantenimiento práctico y la recreación simbólica de la identidad étnica. Estas agrupaciones, claramente privilegiadas en términos políticos, ofician también de élites " intelectuales ». Sus integrantes suelen considerarse conocedores sin parangón de la lengua. La familia cacical considera que su modo de expresarse - tanto la sintaxis como la semántica y la pronunciación - es más « tradicional » y " puro » que el de los « entreverados » con chiriguano o criollos. Esto puede relacionarse con la importancia de la oratoria en la legitimación cotidiana de la jefatura, pero también con el hecho de que es entre los miembros de las familias cacicales donde se encuentra la mayor parte de los narradores "autorizados » de los mitos, recopiladores nativos de la tradición e investigadores de la cosmología y sus secretos, lo cual no pocas veces los convierte en informantes profesionales de los eventuales antropólogos.

Como el lenguaje, por así decirlo, no sólo encarna un caudal de conocimiento difuso sino también instituciones, no es insensato que los miembros de las élites aparezcan - ante sus ojos y ante los de los demás - como auténticos « guardianes » $\mathrm{o}$ « administradores » del espacio y el tiempo colectivos. Antes de desarrollar el punto, aclaremos que la distinción entre las dos dimensiones es tan sólo una conveniencia expositiva, pues, como veremos, ambas se conjugan en una misma estructura ideológica. 
Hoy no puede afirmarse, como en tiempos de Nordenskiöld (2002, pp. 212213), que las tierras « pertenezcan » al jefe. Pese a que las familias cacicales suelen poseer tierras de cultivos un poco más extensas que el resto, la propiedad de las tierras es comunal. Sin embargo, existe una instancia más o menos formal en la que cada joven recién casado dialoga y luego conviene con el cacique cuáles serán las tierras de cultivo que le corresponden. Del mismo modo, el cacique es quien formalmente «da » las tierras a los chané de otras procedencias que quieran asentarse en la comunidad. Los miembros de la familia cacical, como signo inequívoco del estatus y la responsabilidad que conlleva su investidura, se presentan como celosos custodios de los títulos comunitarios de las tierras, haciendo especial énfasis en que los mismos no deben « salir » de la familia. No obstante, la administración y la custodia del espacio por parte de la familia cacical parecen estar mucho más presentes en otro plano. Con el correr de los años y la consiguiente decadencia de los líderes guerreros se produjo una suerte de desplazamiento de las funciones cacicales hacia la búsqueda - mitad real, mitad mítica de los títulos de tierras y la reivindicación de la llamada " propiedad originaria ». Es razonable que los caciques estén particularmente dotados para esta misión, puesto que su linaje es el reservorio privilegiado de la toponimia que sirve como contexto de referencia para la tradición oral y la memoria colectiva.

Pese a que Nordenskiöld (2002, p. 155) menciona que a muchos lugares se les otorgaban antiguamente los nombres de los jefes locales, en la actualidad parece que los referentes de la toponimia se deben más bien al recuerdo de sus gestas legendarias. La familia cacical es la que posee un conocimiento más articulado y consistente del territorio de varios miles de hectáreas que antes ocupaban los chané. No es menos decisiva la contribución del linaje cacical a la administración colectiva de la memoria y el tiempo. Sus miembros poseen una concepción de la temporalidad distinta - al menos en grado - de la del resto de la gente. El horizonte temporal que posibilita el recuerdo de las genealogías y sus ramificaciones - es decir la conciencia de un tiempo que podríamos calificar de " estructural »-les permite articular una conciencia diacrónica inédita, excepcional. Es difícil que el chané común recuerde el nombre de su propio abuelo. Por el contrario, las líneas " aristocráticas », asociadas con la sucesión, la herencia y la memoria de « hitos » marcados por las acciones de los sucesivos big men, constituyen no sólo los linajes que regulan la afiliación sociológica, sino también una especie de regla mnemónica que permite a ciertas familias extensas mantener el recuerdo de sus parientes lineales y, a partir de ellos, de los colaterales de las generaciones precedentes.

Un ejemplo concreto es la onomástica. En la ideología chané, las preocupaciones respecto de los nombres personales responden a dos ideales muy explícitos : que los nombres no se repitan fuera de la familia y que, a la vez, no se olviden. Se admite la posibilidad de usar el nombre de un pariente lineal o colateral lejano en el tiempo siempre y cuando se pueda rastrear su conexión genealógica, lo que 
no siempre es posible. La revisión de las genealogías y el testimonio de los mismos chané permiten aventurar la existencia de stocks onomásticos que pertenecen a cada una de las «familias ». El concepto subyacente de « familia » (cherentara), así, parece asociarse más con la noción de " estirpe » que con algún grupo sociológico de existencia independiente. Pero es preciso recordar que las familias que mantienen una memoria genealógica de cierto alcance temporal, y que por ende cuentan con un repertorio onomástico más amplio, constituyen un caso excepcional. La homonimia vincula a las personas con sus parientes de prestigio ; $y$, en consecuencia, el alcance de los lazos que establece parece inseparable de la importancia conmemorativa que para los chané tienen los linajes privilegiados (Villar y Bossert 2004).

El prestigio de la élite cacical no se revela solamente en la temporalidad - por así decirlo « egocentrada »-de las genealogías que cada individuo puede llegar a conocer. También desempeña un papel crucial en las « historias de los antiguos », que los chané engloban en la categoría de arakae miari. La función mnemónica que desempeña el linaje aristocrático, y la línea de sucesión de los caciques y sus acciones, conforman una estructura de « hitos » mediante la cual se ubican en el tiempo aquellos eventos que los chané consideran significativos. Pese a que difícilmente cada individuo conozca la totalidad de la secuencia y de sus contenidos, mediante consultas, recuerdos fragmentarios y asociaciones parciales sí puede reconstruirse un desarrollo histórico bastante consistente.

Muchos chané diferencian, por un lado, los « caciques guerreros » de Cochou a Tupare, que defendieron la tierra frente a los invasores chiriguano, toba, chorote y wichí ; y, por el otro, los llamados « caciques de comunidad », desde Acharei hasta los actuales mburuvicha. Nordenskiöld no llegó sino a conocer a los hijos de Cochou, y su jefatura parece el máximo horizonte diacrónico concebible para cualquier chané, más allá del cual los sucesos se diluyen en el mundo del mito. Jinete astuto, invulnerable y ubicuo, Cochou es recordado por su defensa del territorio ante los chiriguano que invadían desde Bolivia, y frente a los chorote, toba y mataco-wichí, que lo hacían desde el este, migrando desde el Chaco. La predilección elitesca de los chané parece revelarse una vez más en el hecho de que todos los testimonios coinciden en describir una tropa pequeña pero selecta e invencible, compuesta en algunas versiones por el cacique y siete jinetes y en otras por doce. En un episodio digno de un mito, mientras la gente festeja luego de una victoria, el héroe, acaso atraído por los iya (« dueños » de las cosas), desaparece con su mujer en el río Itiyuro, y se rumorea luego que reaparece en el Paraguay.

Uno de sus hijos, Mocapoy, informante de Nordenskiöld a principios del siglo $\mathrm{xx}$, parece haber sido un hábil diplomático, y con él se inaugura la lucha por las tierras. Ante el acoso de los karai (blancos), acompañado por unos pocos hombres de confianza, emprende un viaje atravesando el Chaco, guiado por un toba llamado Aychoréke, tratando de llegar a Buenos Aires. Tras muchas peripe- 
cias en las que no falta la dramática traición del guía, llegan a Buenos Aires, donde son recibidos por el gobierno. La vuelta con los documentos que otorgan las tierras a los chané, con la escolta del ejército nacional, es un episodio épico que no cesa de ser narrado. Pero los documentos se perdieron. Como su padre, Mocapoy también se ocupaba de vigilar el territorio, y defendió las líneas de aprovisionamiento del general boliviano Magariños contra los contingentes toba y wichí que las hostigaban. En recompensa, el gobierno boliviano le concedió nuevos papeles que legitiman la propiedad formal del territorio ; documentos que, no obstante, otra vez se perdieron. Otros testimonios enfatizan que Mocapoy luchó para que el territorio chané formara parte de la República Argentina, ayudando a las autoridades nacionales a instalar los mojones que delimitan la actual frontera con Bolivia.

Hemos recabado poca información sobre el período intermedio de la genealogía. Tabariti al parecer vivió en Yembui. Con su hijo Chukuri, originario de El Algarrobal, se revive el drama de las invasiones chiriguano, wichí, toba y chorote, que logra finalmente rechazar reuniendo un enorme ejército. Poco o nada sabemos en cambio de Tupare. Acharei, o Centeno Ríos, lleva ya el apellido castellano que sus descendientes hoy mantienen. También viaja a Buenos Aires, en busca del elusivo título de las tierras ; pero se lo recuerda principalmente por haber promovido el asentamiento de una misión franciscana en Tuyunti. En sus tiempos persistían los viejos recelos hacia los chiriguano ; también subsiste el antagonismo con los toba, con quienes las relaciones siempre son tirantes en la frontera oriental. Entre otras cosas se cuenta que Centeno Ríos supo cuándo iba a morir, y que su fallecimiento fue señalado por tres truenos.

Marcos Centeno o Mayari, padre del actual cacique, fortalece durante su gobierno los lazos con los misioneros franciscanos, y persiste en la lucha por las tierras. Cuando murió, Taparindu todavía era menor de edad. El cacique actual tiene un hermano mayor que pudo haber heredado el cargo pero que no era bien visto por la familia - su nombre es Mbokere, «loco»-; además, jamás se interesó por el cacicazgo, al punto de que abandonó la comunidad para no volver. Hasta que alcanzó la edad necesaria, las hermanas mayores de Taparindu se encargaron de las tareas cacicales.

Reservorio privilegiado de la cultura, vínculo directo con la tradición, el pasado y la memoria, no es difícil comprender por qué la pertenencia a las familias cacicales implica deberes « diplomáticos ». Sus miembros asumen tácitamente la tarea de llevar adelante las relaciones con el Otro, oficiando de « cara » del grupo ante los extranjeros o los visitantes, y a la vez criticando ásperamente a quienes debieran hacerlo pero no pueden lograrlo.

En definitiva, toda una serie de datos hace pensar que existen importantes diferencias entre la élite cacical y la gente común ${ }^{2}$. Los chané sostienen de forma muy explícita que el mandato " es hereditario », « de línea »; que no es "para cualquiera », que es un asunto " de sangre » e incluso « de raza »; y que, como 
consecuencia, los líderes deben pertenecer a los linajes tradicionales. El sentido de pertenencia o aun de cercanía genealógica a la élite es motivo de evidente orgullo $^{3}$. Estos lazos no necesitan ser demasiado cercanos : una anciana nos relató, orgullosa, que uno de sus tíos había sido hijo de Tabariti, y que ella había recibido sus tierras de manos del mismo Acharei. En las actitudes cotidianas de los chané, por otra parte, no es difícil percibir cierto deseo de hipergamia real o simbólica. El hecho de estar inscripto real o ficticiamente en la élite, que es lo mismo que ser pariente de sangre o afinidad de los grandes hombres, es atesorado, pues de alguna manera significa ser « más » chané que el resto ${ }^{4}$.

Todo hace pensar que la continuidad del « caciquismo », tal como la conciben los chané, reside en la transmisión de una serie de prerrogativas a través de las generaciones. Si bien no puede afirmarse que la « línea » de sucesión, descendencia o herencia sea siempre directa, ni carezca de ramificaciones y lateralidades, sí asume en su ideología una forma inequívoca. Real o clasificatoria, objetiva o ficticia, los años ven producirse una afiliación progresiva de las generaciones a una sucesión lineal de caciques que se piensan como descendientes directos los unos de los otros. Pese a que existen datos que indican que Mocapoy se apellidaba Cardozo, a diferencia de los últimos caciques que se llaman Centeno, o que los distintos líderes de la dinastía eran originarios de diferentes procedencias, el punto es que la sociedad chané ha preferido representar la historia de sus caciques como una línea ininterrumpida y directa que se remonta hasta el mítico Cochou : en una palabra, como un linaje en sentido clásico. De una generación a otra se transmiten bienes materiales ${ }^{5}$, como el acceso privilegiado a las tierras de cultivo, a los puestos de trabajo estatales o privados, y en particular a los preciados cargos de maestros bilingües en las escuelas de cada comunidad ; también bienes simbólicos como los nombres, o el prestigio que otorga una legitimación histórica inédita para el hombre común ; y también lealtades, enemistades políticas, envidias, acusaciones de brujería y distintos tipos de enfrentamientos.

Sin embargo, no todo el éxito del linaje « real » puede explicarse por mecanismos ideológicos, por excepcionales que sean. Más allá del aparato simbólico, discursivo y material que permite legitimar a quienes alcanzan un poder inédito, es preciso comprender también aquellos procesos que hicieron que algunos lo lograran y otros no ; por qué un grupo determinado acaparó poder sociopolítico no sólo en una comunidad, sino proyectando su influencia en el nivel supracomunitario, mientras otros se segmentaron, dividieron o esfumaron.

Es probable que, como se desprende de la historia local, la propia necesidad de los karai de tratar con una autoridad más centralizada y representativa haya contribuido con el correr de los años a que el mburuvicha guasu (« jefe grande ») y su linaje hayan acentuado su poder. Pero también sabemos que los caciques chané y chiriguano administraban a la perfección el juego de las alianzas en busca de ventajas políticas (Susnik 1968 ; Braunstein 1983). Los capitanes apelaban a diversas estrategias, expandiendo o contrayendo los lazos de alianza según las 
conveniencias coyunturales. Explotando al máximo principios estructurales como la poligamia, la endogamia de rango, las repeticiones de alianzas y el matrimonio avuncular, los grandes jefes intervenían estratégicamente en la sucesión de los caciques subalternos, ubicando a sus propios parientes a la cabeza de los grupos locales.

Revisemos, primero, las estrategias expansivas. Las informaciones de la narrativa oral chané sugieren que antiguamente el territorio chané se dividía en varios tëta, término que los informantes glosan como " barrio », " familia » o " comunidad». Cada tëta tenía su mburuvicha, que respondía a su vez a un mburuvicha guasu, el cual parece haber pertenecido siempre al tradicional linaje de Tuyunti. Esto parece indudable : los chané de otras comunidades conocen todos las hazañas más notables de Cochou o Mocapoy ; en cambio, las informaciones sobre los jefes de menor jerarquía nunca son tan precisas ni compartidas. Una práctica extendida fue tradicionalmente la poliginia, prerrogativa característica de los big men : tener muchas mujeres significaba disponer de una gran fuerza de trabajo, y por ende de una capacidad inusual para celebrar convites de chicha. Sabemos también que los capitanes regionales chané digitaban el nombramiento o la sucesión de los caciques subalternos, ubicando a sus propios hijos, hermanos o primos a la cabeza de los grupos locales. Uniendo en matrimonio a sus parientes de confianza con muchachas de las élites comunitarias, el linaje principal lograba un control estricto sobre la totalidad del territorio ; es el caso, por ejemplo, del abuelo del actual cacique de Tuyunti, quien nombró a su propio hermano como capitán de la comunidad de Piquirenda Fátima.

Pero también, cuando las circunstancias lo exigían, los grandes caciques practicaban una política inversa de clausura o contracción de la red afinal. Una posibilidad era apelar a las repeticiones de alianzas, práctica típicamente chaqueña que fortalecía de generación en generación los lazos entre determinadas familias ${ }^{6}$. Otra posibilidad era el matrimonio avuncular. Los datos etnohistóricos, así como el uso de la terminología de parentesco - que enfatiza no sólo el carácter estrictamente afinal de la relación entre el MB y ZD y luego su papel crucial como garante de cualquier relación de identidad étnica - hacen pensar que existió una marcada preferencia por el matrimonio avunvular en los linajes cacicales ${ }^{7}$. El matrimonio con la hija de la hermana - prerrogativa, con la poliginia, de los grandes jefes - comportaba ventajas evidentes : consistía en una estrategia atractiva en tiempos de guerra, y más en una sociedad con requisitos uxorilocales y a la vez una ideología de lealtades patrilineales. El capitán evitaba vivir en una familia extraña, acaparando a la vez más fuerza de trabajo (mujeres que cultivan y elaboran chicha para celebrar convites) y más apoyo político y militar (" sobrinos » que le deben respeto y lealtad). Como resultado, su linaje se volvía más numeroso, fuerte e indiviso ${ }^{8}$. En este contexto, se comprende la insistencia en la endogamia de rango y las preferencias por las alianzas entre estirpes encumbradas. 
En definitiva, el examen del funcionamiento de las estructuras de parentesco y su utilización estratégica por parte de individuos prestigiosos nos permite imaginar cómo, en el pasado, un linaje pudo haber extendido su influencia en el nivel supracomunitario, constituyendo la base sociológica sobre la cual a posteriori se pusieron en práctica los distintos mecanismos de legitimación ideológica del linaje « real ».

En la actualidad, sin embargo, el cacique ya no está solo : debe mantener vínculos con las asambleas comunales, con los segundos capitanes y con las « nuevas élites » locales. Paralelamente al cacique, funciona en cada una de las comunidades un Consejo Comunitario local, que se organiza con cargos electos de presidente, secretarios, tesoreros, vocales, etc. Semanalmente, se reúne bajo la forma de una asamblea encargada de tomar decisiones en cuanto a las relaciones de la comunidad con el exterior, y también de administrar los planes laborales y las ayudas económicas que eventualmente puedan captarse. Pero aunque los cargos en este tipo de organizaciones son teóricamente electivos, y constituyen de alguna forma una carrera abierta al talento, la más ligera comprobación estadística revela que los big men y sus familiares - los miembros de las viejas élites mantienen en sus manos una porción considerable de los mismos. El cacique también debe trabar relación con el " cacique segundo » que existe en algunas comunidades. En Tuyunti, este personaje es el sobrino (ZS) del mburuvicha, y no hay demasiados problemas entre ellos. El cuadro general, en definitiva, remite una vez más al acaparamiento de cargos por los miembros de la élite tradicional.

\section{Los izoceños de Bolivia}

Los izoceños llaman a la dinastía de los « Grandes » (tuvicha), ñemunia ete («familia por excelencia ») o bien añetetee ñemunia (« verdadera familia »). Estas expresiones suelen traducirse como «familia real» en español ; muchas veces, también, la palabra mburuvicha («capitán», "dirigente ») se traduce como « rey », " reina », o " princesa » (Riester 1998). La ñemunia ete incluye a todos los « parientes » cercanos o lejanos, reales o ficticios, de la familia Iyambae (« sin dueño »). Esta familia gobierna la zona al menos desde mediados del siglo XIX ; y los dirigentes actuales, que llevan el apellido castellano Barrientos, no son sino una rama, o un linaje, de la misma (Figura 2).

Actualmente existen varios « linajes reales », todos considerados herederos del mburuvicha guasu (« capitán grande ») José Iyambae. Si bien fue un personaje histórico real, José Iyambae aparece casi como un antepasado mítico. Es la raíz ancestral de la familia y su referencia obligada ${ }^{9}$. Se conocen algunos de los nombres de sus predecesores (Chótchori, Sapuruke, Uchuapi, Mboira), pero poco o nada se sabe de sus hazañas o sus lazos familiares. La historia de la dinastía empieza, pues, con José Iyambae, y el parentesco con él es el común denominador de la «familia real » entera ; las diferencias aparecen luego, al segmentarse los distintos linajes formados por los descendientes de sus hijos. 


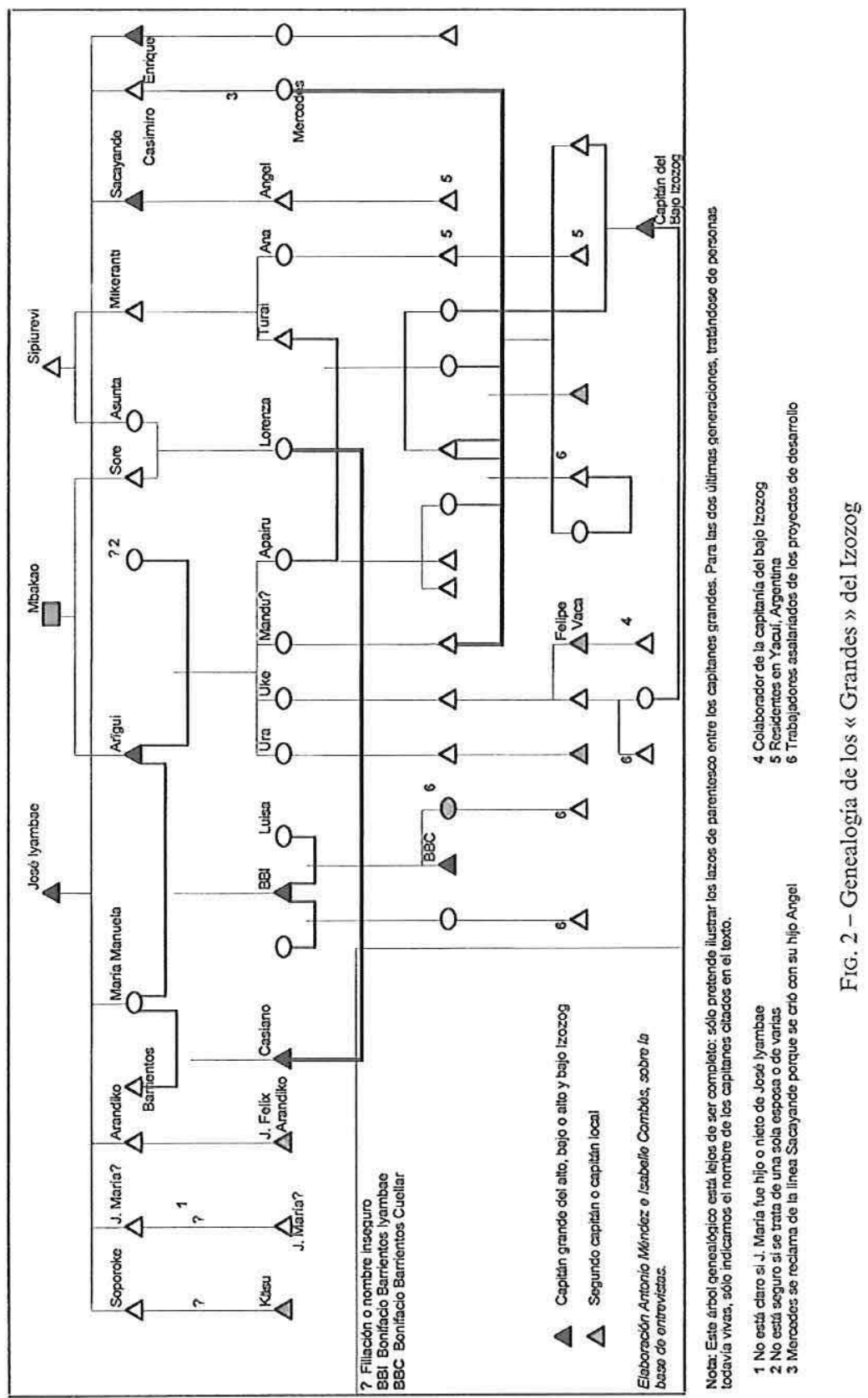


A estos linajes pertenecen hoy la mayoría de los mburuvicha comunales y supra-comunales; a ellos pertenecieron, también, los grandes chamanes de antaño, y pertenecen hoy los « dueños del saber », conocedores de la « historia de los antiguos ». A estos linajes privilegiados pertenecieron, en definitiva, todos los grandes hombres - la expresión es del mismo Nordenskiöld (2002, p. 213). A ellos pertenece hoy, por último, la mayoría de la gente que trabaja para las organizaciones de desarrollo o los proyectos estatales.

No cabe duda de que la « familia real » goza de mucho respeto, consideración y de privilegios. Los cultivos de la familia del capitán grande son atendidos por los comunarios; cuando se carnea una res, las mejores piezas son para el mburuvicha y sus acólitos. Monopolizando los cargos asalariados, los miembros de los linajes "reales » también se vuelven más prósperos y aun afirman más visiblemente su diferencia. Hay conflictos y rivalidades entre los linajes elitescos, o entre estos mismos linajes y los commoners, pero es preciso aclarar desde el comienzo que estas tensiones no cuestionan el sistema en sí. Se cuestiona al rey pero no a la realeza ; o, en otras palabras, los conflictos están claramente dirigidos a la redistribución de los privilegios de esta aristocracia, y no a su supresión.

La legitimidad hereditaria de la aristocracia es concebida como una cuestión de " sangre », y se podría decir casi de « raza » (véase Hirsch 1991, p. 108). En consonancia con esta ideología, la praxis matrimonial consiste en una endogamia de alianzas preferenciales entre linajes "reales ». Casarse " afuera » no está prohibido ; pero implica, para las generaciones futuras, un debilitamiento de la sangre y una consiguiente pérdida de poder. En las primeras décadas del siglo xx, Enrique Iyambae, hijo de José, desposó una mujer yart, es decir descendiente de prisioneros de guerra chiriguano que servían como esclavos en el Izozog. Si bien fue un jefe respetado y tenedor de un título formal de "capitán grande », la descendencia de Enrique, cargando con su oprobioso origen yari, no desempeñó ya ningún papel en la política local. Su nieto, de padre desconocido, se apellida Iyambae, y es reconocido como pariente por los demás miembros de la « familia real »; pero nunca tuvo el poder ni gozó de los privilegios de su linaje. Otro miembro de la dinastía se casó con una mujer chiriguano, y afirma él mismo que sus hijos "ya no son de sangre pura ». Un contraejemplo es el de un nieto de Casiano Barrientos, miembro de la « familia real » por parte de madre pero hijo de un hombre « común », y que se casó con una mujer de otro linaje « real ». Sus hijos - lo admiten todos - son «más puros » que él. De alguna forma, la hipogamia de su madre se subsanó con su propia hipergamia, y utilizar estos términos no es un abuso de lenguaje, pues corresponden exactamente a las representaciones de los propios izoceños. La endogamia de la « familia real » es la que permite la transmisión del poder y de los privilegios. Por el contrario, la exogamia es sinónimo de hipogamia para un "noble »; y, por supuesto, de hipergamia para un eventual comunario. 
$\mathrm{Si}$ bien todos se reconocen emparentados genealógicamente, los diferentes linajes también se oponen en una lucha abierta por el poder. En la actualidad, este conflicto se cristaliza en la rivalidad regional entre el « Alto » y el « Bajo » Izozog; es decir; entre las comunidades de río arriba y las de río abajo. El «capitán grande del Alto y Bajo Izozog », Bonifacio Barrientos Cuellar, sólo posee en realidad el título de " capitán grande del Alto Izozog ». Antes que él, su padre, Bonifacio Barrientos Iyambae estaba en la misma situación, pero en la práctica llegó a ser - abusivamente, según los miembros de los demás linajes - capitán grande de toda la zona. Las circunstancias históricas bien pueden explicar la «toma de poder» de Bonifacio padre ; en particular, el estado lamentable de abandono y desorganización provocado en el Izozog por la guerra del Chaco (1932-1935). Su heredero, Bonifacio hijo, asume en la práctica el papel de representante de todo el Izozog, y se encuentra reconocido como tal por el gobierno y las organizaciones de desarrollo. No obstante, varias figuras se levantaron en el Bajo Izozog en contra de Bonifacio, reclamando el poder para sí mismos. Y estas voces discordantes pertenecían todas a diferentes linajes « reales ». Hoy el adversario principal de Bonifacio hijo no es otro que el último heredero (clasificatorio) del linaje Sacayande ${ }^{10}$. A finales del siglo XIX cundió la rivalidad entre el mismo Sacayande y el abuelo de Bonifacio Barrientos Cuellar, Arïgui. Es decir que no sólo los linajes se enfrentan, sino que transmiten, al mejor estilo de la vendetta italiana, sus odios y sus rivalidades. Los argumentos del linaje Sacayande son hoy los siguientes :

1) Bonifacio es « menos legítimo » que el descendiente de Sacayande porque pertenece al linaje Arïgui ${ }^{11}$. En la acusación se entremezclan dos argumentos distintos. El primero es expresado en términos de parentesco : hasta donde llega la memoria genealógica, Arïgui fue sólo un aliado por afinidad de la «familia real », pues no pertenecía a ella «de sangre ». Al ser fruto de matrimonios hipogámicos, Bonifacio Barrientos sería entonces « menos puro » que los descendientes de Sacayande, y sólo podría reclamar su pertenencia a la «familia real » por parte de su abuela (FM, y esposa de Arïgui ; ver figura 2). El otro argumento es netamente político : como lo sugieren los documentos escritos tanto como numerosas tradiciones orales, Arïgui habría " usurpado » el título de capitán grande en 1887, desplazando a los herederos legítimos, hijos de José Iyambae. De manera muy oportuna para Arïgui, Sacayande murió embrujado - según alegan hoy sus descendientes -, y no hace falta demasiada imaginación para encontrar el culpable en Arigüi. Con escaso reconocimiento y legitimidad, y acusado de lucrar con el envío de gente a la zafra, Arïgui fue expulsado del Izozog a inicios del siglo xx. Hoy, más de un siglo después, la rivalidad entre los descendientes de ambos protagonistas persiste, con los mismos argumentos y tal vez las mismas consecuencias : la muerte sospechosa del padre del líder del Bajo, en 2003, fue atribuida a un acto de hechicería. 
2) Utilizando también argumentos más al gusto del día, el linaje Sacayande alega que el Bajo Izozog se encuentra más descuidado, en términos de desarrollo, que el Alto Izozog, beneficiario durante los últimos años de la gran mayoría de los proyectos. Se dice que Bonifacio Barrientos, del Alto, favorece a su zona de origen, y mantiene al "feudo » del Bajo en un perpetuo estado de pobreza y aislamiento. Sin embargo - dicen los bajeños - el Bajo Izozog es una zona más « tradicional » que el Alto : más izoceña, más pura. No está invadido, como el Alto, por los ava-chiriguano ; y está menos expuesto, a diferencia de los dirigentes del Alto que viajan constantemente a la ciudad, a las influencias karai. A las acusaciones de aculturación se añaden también acusaciones de corrupción, eco de las empleadas hace más de cien años contra Arïgui. Finalmente, se sostiene que el Bajo Izozog es la sede « tradicional » del poder político izoceño, puesto que allí vivía el mismísimo José Iyambae ; a lo cual Bonifacio Barrientos responde que Güirayoasa o La Brecha, sede actual de la capitanía en el Alto Izozog, es la capital cantonal.

Las rivalidades entre los distintos linajes « reales » izoceños traducen, expresan o disimulan una serie de conflictos. Se trata de rencillas por el poder político que también presentan un tinte territorial muy marcado. Las rivalidades también se expresan en términos étnicos, oponiendo a los izoceños « más puros » del Bajo con los "más ava » o "más karai » del Alto. No se trata de conflictos entre iguales. Si bien teóricamente todos tienen el mismo derecho de reclamarse descendientes de José Iyambae, el linaje Sacayande quiere afirmar su mayor legitimidad en términos de una proximidad genealógica. Ideológicamente un punto clave parece ser el idioma en el cual se expresan los conflictos : el parentesco y la " sangre » por una parte, y la legitimación histórica por otra. En la práctica el poder (la autoridad, el reconocimiento por parte de los de « afuera » y - factor no menos decisivo - el manejo del dinero) se encuentra en manos de Bonifacio Barrientos, y por consiguiente del Alto. « Alto » $\mathrm{y}$ « Bajo » Izozog son, pues, términos topográficos, pero expresan también una clara asimetría en el plano político.

Esta dinámica sociológica que rodea a la ñemunia ete, o más precisamente a la rivalidad entre las diferentes ramas de esta familia, no es nueva, ni propia de un único momento histórico. El Izozog fue poblado a inicios o mediados del siglo Xvi por esclavos chané (tapi) que huían de sus amos guaraní (Matienzo 1918 , pp. 54-55 ; Combès ed. 1999 ; Combès y Lowrey 2004). Es más que probable, no obstante, que no se trataba de una zona desierta antes de la llegada de los fugitivos, sino más bien el hogar de algunas comunidades chané, " puras » en comparación con los tapi ya guaranizados que llegaron luego. Los izoceños - autodenominados tapi - reconocen, todavía hoy, a familias que identifican como "chané » en el Izozog. Se trata de familias cuyo estatus no difiere en absoluto del de las demás, pero que no son consideradas como tapi. Decir que los tapi izoceños « son » chané es entonces una observación cierta, pero incompleta : 
la hipótesis de un poblamiento chané « original » del Izozog permite, por otra parte, comprender la identificación actual, por parte de los tapi izoceños, de otros " chané » no tapi, es decir no ex esclavos y menos guaranizados (o guaranizados luego, por los tapi). Recientes sondeos arqueológicos pueden apoyar esta hipótesis : identificaron en los bañados del Izozog, es decir en el extremo Bajo, varios sitios cuya cerámica presenta ciertas similitudes con las culturas del Mamoré en el actual departamento del Beni, fechadas entre 300 a 1000 d.C. (Dames y Moore 2001, cap. 6). Esta similitud sugiere que los « pueblos de los bañados » tuvieron un lejano origen amazónico. Los autores no mencionan, curiosamente, a los chané ; si nos acordamos, sin embargo, que los chané eran parientes del grupo mojeño del Beni, y que pertenecían a la misma familia lingüística, no parece descabellado suponer que estas cerámicas son restos y evidencias de la ocupación temprana, por parte de los chané - o al menos, más allá de las etiquetas, por un grupo arawak - del extremo Bajo Izozog. En todo caso, los chané "puros » fueron rápidamente dominados, al menos en términos demográficos, por los tapi que llegaron desde el pie de monte, y que hoy constituyen indiscutiblemente la mayoría en el Izozog. Es probable que los chané «verdaderos» hayan sido empujados, poco a poco, hacia el extremo Bajo Izozog, mientras los tapi ocupaban el Bajo (sede, de hecho, de la familia « real » tapi) y parte de lo que es hoy el Alto.

Carecemos, para esta época, de información fidedigna sobre la aristocracia izoceña. Lo que sí vale la pena subrayar es que los (escasos) relatos sobre el primer poblamiento de la región hablan de una mburuvicha, Kaa Poti, como madre del " primer » Iyambae ; así, la « familia real » habría existido " desde los orígenes » (Combès ed. 1999 ; Combès s.d.). Desde los mismos orígenes, se perfila la división del territorio en zonas bien delimitadas : el extremo Bajo, y el Bajo de hoy ${ }^{12}$, división que se traduce a su vez en una oposición étnica y asimétrica entre chané " puros » y tapi guaranizados. De hecho en el siglo xIX, cuando aparece más documentación sobre la «familia real » y sus linajes, los primeros conflictos registrados oponen el extremo Bajo y el Bajo Izozog ${ }^{13}$. Un ejemplo : en 1865, José Iyambae y un tal Gregorio Callumbare [Kayumbari] estaban « disputándose entrambos el título de Capitán Grande de todo el Ysoso » (MHSC 2/82, 14-VII1865) ; Kayumbari era capitán de Güiraendi en el extremo Bajo Izozog (MHSC 2/85, 4-XI-1967) y sin hacer caso a la autoridad de Iyambae, llegó hasta la sede de gobierno para quejarse de los ganaderos blancos del Izozog (MHSC 2/85, 4-XI1867).

Los títulos expedidos por la prefectura parecen ser sólo un reconocimiento formal de otro respaldo más legítimo otorgado por las mismas comunidades ; son, sin embargo, pruebas que alimentan la llama de los conflictos entre los distintos linajes de la «familia real ». Si bien José Iyambae es reconocido hasta hoy, por todos, como un legitimo capitán grande del Izozog, no cabe duda de que pudo conservar el cargo gracias al apoyo de la prefectura de Santa Cruz ; como 
no cabe duda, tampoco, de que tuvo que enfrentar a varios pretendientes al trono, entre ellos Kayumbari.

Conflictos de linajes, conflictos territoriales, conflictos de poder, conflictos de asimetría : como Bonifacio Barrientos hoy, José Iyambae goza del reconocimiento de las autoridades nacionales. El Bajo Izozog es la sede de la «capitanía grande », y domina al extremo Bajo ; territorio incluso que José parece haber dado, en una verdadera repartición de feudos, a uno de sus hijos (Albó 1990, p. 141).

En mayo de 1871 un nuevo capitán grande es nombrado por la prefectura de Santa Cruz: José Arïgui Bacao. Este título se expide « conforme a los deseos manifestados por los vecinos de esa localidad » : es decir; los deseos de los ganaderos blancos de la zona (MHSC 3/96, 4-V-1871). En diciembre del mismo año, sin embargo, y en gran parte debido a quejas de Iyambae según puede entreverse en los fragmentarios archivos, la situación cambia otra vez : el prefecto nombra nuevamente a Iyambae como « Capitán Grande del Ysoso [...] desde el punto de Ariyoé al Norte, con separación e independencia del territorio del Sud que continuará bajo el mando de su Capitán José Aringui Bacao » (MHSC 3/96, 15-XII-1871). Este documento es el primer ejemplo histórico de la división del Izozog en dos zonas, norte y sur, o respectivamente Bajo y Alto, siguiendo el curso del río Parapetí. En esta época, sin embargo, el « Bajo » incluye gran parte del extremo Bajo, y el « Alto » gran parte del « Bajo » actual. No puede negarse la influencia de la prefectura en esta partición ; pero lo que sabemos sobre los conflictos izoceños nos permite, no obstante, suponer que los karai fueron más bien utilizados por ellos para sus propias luchas de poder.

El cogobierno Iyambae/Arïgui fue a todas luces efímero y poco considerado por la prefectura, que sigue dirigiéndose únicamente a Iyambae en los años que siguen. En 1887 sin embargo, Arïgui seguía siendo un capitán muy importante (Thouar 1997). En los años siguientes, después de la muerte de José Iyambae, surge la disputa entre Sacayande, heredero legítimo, y Arïgui. Este conflicto tal vez haya sido precedido por otro, entre el mismo Arïgui y un hermano mayor de Sacayande, Soporoke, rebelde asesinado por los karai de la zona con la complicidad de varios tapi. Thouar (ibid., p. 372) relaciona explícitamente el problema de la elección de Arïgui con la muerte de Soporoke.

Luego, la expulsión de Arïgui, a inicios del siglo xx, deja el Izozog sin capitán grande por varios años : «los chané del Parapetí ya no tienen jefe principal », escribe Nordenskiöld (2002, p. 215). Invadidas por las haciendas karai, las comunidades, antes asentadas en la ribera derecha del río Parapetí, comienzan a trasladarse hacia la orilla izquierda (Combès ed. 1999). Como resultado la zona hoy conocida como Alto Izozog, cobró cada vez más importancia. El movimiento se acentúa durante el siglo $\mathrm{xx}$, primero con el regreso de los comunarios tras la guerra del Chaco y la instalación de la mayoría de ellos en el Alto Izozog ; luego, con una fuerte inundación en 1959, que destruyó prácticamente todas las 
comunidades del extremo Bajo. Es revelador que entre los pobladores del Alto Izozog figuren muchos ava-chiriguano, llegados de las comunidades de San Antonio del Parapetí. Isiporenda y Karaparí, las primeras comunidades izoceñas del Alto, son comunidades ava-chiriguano, antes « fronteras » del Izozog, y hoy (desde 1965) incorporadas a la capitanía. El ascenso del Alto Izozog es, pues, inversamente proporcional con el ocaso del extremo Bajo. Si en 1875 podían contarse más de veinte comunidades en esta última zona, hoy sólo existen tres ; son grupos karai o mestizos, con un fuerte porcentaje de habitantes criollos.

Una década antes de la guerra del Chaco surge una nueva figura carismática : Enrique Iyambae, hijo de José. Su mérito fue iniciar, treinta años antes de la reforma agraria de 1952, los trámites de los títulos agrarios. Esta época marca además la segunda aparición " oficial » de la división entre Alto y Bajo Izozog. De hecho, los izoceños contemporáneos hacen remontar esta división a 1923 solamente, y no mencionan nunca el cogobierno de 1871. Este olvido es real, puesto que se advierte que aquellos acontecimientos no tuvieron consecuencias inmediatas. Pero tal vez se trate también de un olvido "diplomático » : evitar mencionar los problemas enfrentados por Iyambae y el "golpe de Estado " provocado por Arïgui contribuye no poco a consolidar la capitanía actual.

Enrique llega así a compartir oficialmente el poder político, y lo hace con su sobrino, Casiano Barrientos. Se trata de una relación asimétrica : el capitán del Alto (Enrique) es más respetado y más poderoso que el del Bajo (Casiano). En los trámites de tierra que se inician el capitán del Alto Izozog interviene siempre, ya se trate de comunidades del Alto o del Bajo Izozog; Casiano Barrientos, por el contrario, sólo aparece en los trámites de las comunidades bajeñas, y no interfiere en aquellos otros que están fuera de su jurisdicción (IZO-1, IZO-3, IZO-9). Un matiz étnico existe también, pues surge la nueva oposición étnico-territorial entre el Bajo " más tapi » y el Alto " más ava », que desplaza poco a poco a la antigua diferencia entre chané « más puros » y tapi más guaranizados.

En el caso del cogobierno entre Enrique y Casiano no parece haber habido ningún conflicto. Podemos aventurar una sugerencia al respecto : Casiano Barrientos, hijo de la hermana de Enrique, María Manuela, fue un hombre «sin padre ", o casi, pues su padre fue un comerciante karai, Juan Barrientos, que murió en 1892 mientras su esposa estaba embarazada de Casiano. Con un padre blanco difícilmente incorporable a la dinastía « real », Casiano tenía sin duda menos legitimidad que Enrique. Su ascendencia karai le fue reprochada por un grupo de izoceños que quisieron acercarse al ejército paraguayo durante la guerra del Chaco. Se alimentaron versiones sobre una supuesta traición de Casiano ; y finalmente fue fusilado sin juicio, al acabar la guerra, por el ejército boliviano ${ }^{14}$.

Poco antes de que estallase la guerra, un incidente obliga a Enrique a dejar el poder y huir hacia la Argentina ${ }^{15}$. Casiano quedó como único capitán, aunque acompañado por su medio hermano, Bonifacio Arïgui. Las relaciones entre Enrique y Bonifacio eran pésimas. Una versión recogida por Silvia Hirsch (1991, 
p. 154) muestra que con la salida de Enrique se reavivan las rencillas inmemoriales entre los linajes : habría habido una disputa por el gobierno entre Casiano y un capitán y chamán local del extremo Bajo, Käsu. Käsu era, según nos contó una única persona en el Izozog, el hijo de Soporoke y nieto de Iyambae : representante, en suma, de otro linaje tal vez « más legítimo » que el de Casiano.

La guerra del Chaco culminó en el Izozog con la dispersión de las comunidades y de su gente, con la pérdida de todos los cultivos y el fusilamiento de Casiano acusado de traición. Luego vuelve Bonifacio Arïgui, que ya en aquella época se hacía llamar Bonifacio Barrientos. Su medio hermano le habría «dado su apellido » durante la guerra, en señal de que " eran de la misma familia » por defender los mismos intereses. Casiano incorporó a Bonifacio en su propio linaje, mejor considerado que el de Arïgui. De hecho, Bonifacio siempre justificó luego su prosapia insistiendo sobre su pertenencia al linaje Iyambae por el lado materno, y sin hacer referencia jamás a ascendencia paterna.

Casi al mismo tiempo que Bonifacio, Enrique también volvió al Izozog. Comenzó así un nuevo cogobierno entre Alto y Bajo Izozog, entre Bonifacio y su tío. La convivencia entre ambos fue difícil y, como antes, sobresale el capitán del Alto (Bonifacio) por sobre el del Bajo (Enrique). En 1953, cuando la subprefectura confirmó su título de "capitán del Alto Izozog ", atribuyó también a Bonifacio el « mando supremo » de todas las comunidades de la zona (IZO-14). El dominio pleno de Bonifacio se vio reforzado en 1958, con la muerte de Enrique Iyambae. A partir de esta fecha los capitanes del Bajo se suceden a gran velocidad sin que aparezca una figura lo suficientemente carismática como para poder contraponerse a Bonifacio Barrientos padre. Este último, así, pudo sellar su dominio en 1965 cuando - mientras gozaba supuestamente de un solo título de " capitán del Alto Izozog » - creó el cargo de « segundo capitán del Alto Izozog ». Este nuevo sistema designa a un mburuvicha guasu regional, apoyado por dos « segundos capitanes » subordinados en cada zona. La historia, así, sigue hoy con Bonifacio Barrientos hijo enfrentado con sus poco exitosos contrincantes del Bajo Izozog, miembros del linaje Sacayande.

Pero la ñemunia ete es ante todo una familia, y es en términos de parentesco que se expresa su dinámica. La capitanía es hereditaria, por más que sea luego ratificada por una asamblea. En estas condiciones, la cuestión crucial consiste en comprobar la mayor o menor legitimidad del pretendiente al «trono » en un contexto en el que diferentes linajes se disputan el poder. ¿ Qué tipo de sucesión « real » existe - si es que existe - en el Izozog?

Algunos afirman que José Iyambae fue hijo de Uchuapi. Esta versión no coincide con lo que dejan entrever las fuentes escritas, donde ambos capitanes son más bien contemporáneos. Sin embargo, prevalece la idea de una sucesión lineal de padre a hijo. De la madre de Iyambae no sabemos absolutamente nada. Siguen luego (sin madre conocida tampoco, y sin que podamos afirmar siquiera que hayan sido hijos de una misma mujer) los primeros herederos suyos : su hijo 
Soporoke, asesinado por los karai ; y su hijo Sacayande, rápidamente suplantado por Arïgui. Demasiado joven en 1887, Enrique Iyambae es otro de los hijos que llegó a ser capitán. En los tres casos sólo podemos afirmar que la transmisión del poder se llevó a cabo siguiendo la línea paterna, aunque sin que esto excluya, en ausencia de datos suficientes, una posible influencia del lado materno.

El caso de Arïgui resulta interesante porque es atípico, siempre y cuando supongamos que existe un tipo claro de sucesión en el Izozog. Muchos dicen que Arïgui « no era nada » - no era capitán, ni pertenecía a la « familia real » - antes de casarse con María Manuela Iyambae. Son versiones que, a nuestro juicio, deben poco a la realidad histórica, y mucho al odio colectivo hacia el personaje y/o su descendiente, el actual capitán grande. José Arïgui tenía como segundo apellido Bacao, nombre de un capitán local en 1855, por ese entonces un probable miembro de la «familia real » (ANB MI 1857 161/52, 27-VIII-1857). Sabemos, por otra parte, que ya en 1871 Arïgui era capitán del Alto Izozog. Cabe subrayar que en 1887, cuando llegó a ser nombrado capitán grande por Thouar, Arïgui no estaba casado todavía con María Manuela : su unión con la heredera de Iyambae tuvo lugar después de 1892. Parece razonable, entonces, pensar que Arïgui sí perteneció a algún linaje « real ». El hecho de que, en las generaciones posteriores, sus hijos y sobrinos se siguieran casando con miembros de la « familia real » (ver Figura 2), parece respaldar esta hipótesis. Sin embargo, la falta de datos no permite excluir otra hipótesis que aparentemente cuenta con la mayor aceptación, excepto claro está del linaje ex-Arïgui, rebautizado Barrientos : la « toma de poder » de Arïgui en 1887, utilizando sin reparo la presencia de Thouar, fue « legitimada » mediante su (posterior) matrimonio con María Manuela ${ }^{16}$. Los descendientes de Arïgui, así, no tendrían más legitimidad que la de su prosapia materna. De hecho, como antes su padre, Bonifacio Barrientos hijo se explaya sobre su ascendencia Iyambae ; y, si bien apela a menudo al nombre de su padre, no mencionó nunca, hasta hacen muy pocos años, a su abuelo Arïgui. En cuanto a Casiano, la situación es más clara todavía : hijo de karai y huérfano de padre, no tuvo nunca más legitimidad que su ascendencia materna.

No se distingue, analizando estos diferentes casos, una línea clara de sucesión para el cargo de capitán grande. Los ejemplos de Bonifacio padre y de Casiano podrían llevar a suponer una preferencia por el lado materno. Pero sería inexacto, o al menos insuficiente, pues tanto Casiano como Bonifacio tuvieron que cargar con su funesta herencia paterna, un karai para el uno y un capitán « ilegítimo » para el otro. Asimismo, los casos de Sacayande y Enrique, si bien no dicen nada en cuanto a una posible herencia por el lado materno, dejan en claro que obtuvieron su « sangre real » por la vía agnática.

No todos los miembros de la «familia real » llegan a ser capitanes grandes, sino que ocupan cargos de honor y prestigio en las comunidades. Observando estos casos para ampliar nuestra muestra de « nobles » izoceños, podemos afirmar que la transmisión del poder y de la « sangre » no es unilineal sino que parece 
ser cognática. Cognática, pero que opera claramente bajo una condición ideológica : para tener acceso a los diferentes cargos, para tener poder, ambos ascendientes, padre $y$ madre, deben ser " nobles », deben « tener sangre ». Los izoceños seguirían, de esta manera, un esquema muy próximo al observado hace más de doscientos años por Sánchez Labrador.

La endogamia de la «familia real» es la condición sine qua non de la transmisión del poder, y la herencia cognática es manejada según los intereses y las circunstancias. Cuando es necesario, el lado materno (María Manuela) predomina para Bonifacio Barrientos ; cuando es necesario, también, sus opositores enfatizan por el contrario su lado paterno ; cuando es necesario, finalmente, Bonifacio, hijo de Arïgui, pertenece al linaje Barrientos. De la misma manera, la « regla » de la uxorilocalidad se flexibiliza según las circunstancias : el hombre izoceño va generalmente a vivir con la familia de su esposa, pero si dicha mujer es una simple comunaria, y el esposo un miembro de la "familia real », lo más probable es que la regla se invierta, evitando la dispersión del poder y los privilegios.

También parece « atípico » el caso de Casiano Barrientos. Es posible esgrimir algunas hipótesis al respecto. Primero, que Enrique Iyambae haya escogido a Casiano precisamente porque le faltaba legitimidad, asegurando de esta forma su preeminencia en el cogobierno. La relación entre ellos, además, es precisamente la analizada por Susnik (1968) y Braunstein (1983), que une al tío materno (tutti) con su sobrino (hii) en una relación asimétrica en la cual el MB goza de una gran consideración y el ZS le debe no sólo lealtad, sino apoyo militar y político. Otra hipótesis consiste en suponer que Casiano estaba dotado de cierto prestigio precisamente por su ascendencia karai; de hecho, lo que más recalcan los izoceños sobre él es su excelente dominio del castellano y su capacidad para tratar con los blancos. Esto no impidió que, cuando quedó solo en el cargo, su herencia karai se volcara en contra suya, a menudo manipulada por otros linajes más « legítimos » : entre los traidores izoceños que denunciaron a Casiano, los testimonio citan a un tal José María Iyambae (Figura 2) que se valió, con seguridad, de su apellido para afirmar sus derechos.

Si la herencia cognática se encauza, interpreta y manipula estratégicamente, lo mismo sucede con respecto a los valores atribuidos a esta herencia. La prosapia karai de Casiano fue sucesiva o simultáneamente reivindicada con orgullo, y luego considerada como una mancha indeleble. El último y más reciente ejemplo de este proceso es la « recuperación » por parte de Bonifacio Barrientos del odiado linaje Arïgui. Fortalecido por su reconocimiento oficial en el nivel nacional, y en respuesta a los que dudan de su legitimidad, el capitán grande está empezando discretamente a revalorizar su herencia. En 2003 encargó un cuadro para la oficina del Izozog en Santa Cruz, que representa a « Bonifacio Arïgui Barrientos Iyambae », su padre, entregándole el mando bajo el auspicio de tres linajes ; ese mismo año, también, el principal campamento del parque nacional 
Kaa-Iya, en Güirayoasa, Alto Izozog y « capital » izoceña, recibió el nombre de Arïgui.

\section{« CASAS » CHANÉ}

Las jefaturas chané no poseen aquella dimensión igualitaria que analizó Saignes apoyándose en las teorías de Pierre Clastres. Todos los hechos apuntan, por el contrario, hacia jerarquías y asimetrías, que corroboran las observaciones más antiguas de Nordenskiöld. Existieron y aún existen « aristocracias » con una dinámica sociológica y una legitimación ideológica definidas, que desempeñan una función fundamental no sólo en el plano político, sino en la articulación de una serie de dimensiones temporales, territoriales, simbólicas y étnicas sobre las que se estructura la continuidad de los chané e izoceños. Pero no basta con afirmar la existencia del fenómeno ; es preciso comprender con cierto detalle tanto la mecánica de su funcionamiento como su notable éxito a través de los años. Para ello, veremos en qué medida el concepto levi-straussiano de « Casa » puede servir para comprender la ñemunia ete izoceña y el caciquismo de los chané.

Conciliando principios aparentemente contradictorios, como hipergamia/ hipogamia, exogamia/endogamia, descendencia/alianza o patrilinealidad/matrilinealidad o derecho de sangre/derecho de elección, la Casa provee un « esquema organizador » que traduce distintos conflictos políticos, reclamos económicos, disputas por el poder y reivindicaciones étnicas o territoriales en un lenguaje único, totalizador y comprehensivo, que construye una legitimidad concebida en términos de parentesco y alianza (Lévi-Strauss 1996, p. 145). Utilizando y subvirtiendo el parentesco para sus propios fines, la Casa combina « intereses reales y genealogías míticas, procurando un fundamento absoluto a las empresas de los grandes » (Lévi-Strauss 1987, p. 162).

Tanto en el caso izoceño como en el chané parece indudable que el idioma en el cual se concibe y se explica la pertenencia a los linajes de prestigio se articula en torno de grados de distancia parental. Este lenguaje encarna una ideología muy explícita de la estirpe, la alcurnia, el rango, la genealogía, la jerarquía y la consanguinidad real o ficticia. En todos los casos se afirma que la pertenencia a las élites cacicales es una cuestión de « sangre », incluso expresada, en español, en términos de « pureza », " herencia » o " raza ». No es casual que los chané y los izoceños escojan estos términos, pues se ajustan con ciertas representaciones y prácticas concretas. En primer lugar, con un ideal prestigioso de « pureza » de sangre. Un pretendiente a la jefatura que sólo pueda reivindicar una ascendencia prestigiosa por el lado materno se encuentra en desventaja por ser «menos puro » que aquel cuya legitimación se ramifica bilateralmente. Al contraer una alianza hipergámica un Ego que « no es nadie » asciende socialmente; de forma complementaria, casarse « afuera » de la familia de prestigio implica debilitar la 
sangre, el prestigio y la consideración. Pero también conduce a redistribuir el poder, lo cual nos conduce al plano de las prácticas. En segundo lugar, pues, existen mecanismos y estrategias orientados hacia las repeticiones preferenciales de alianzas entre linajes de prestigio, la evitación consciente de la dispersión del patrimonio familiar, el nombramiento ritual del heredero, los repartos de «feudos " y el matrimonio avuncular de los big men.

No es raro que esta ideología de la sangre, la pureza y la endogamia se traduzca en términos étnicos. Los chané y los izoceños suelen descalificar a sus eventuales contendientes políticos acusándolos de «chiriguano », "karai », « menos puro », « cruzado » o « entreverado ». En el contexto más abarcativo de las relaciones interétnicas, comprobamos también que los capitanes chané eran concebidos explícitamente como garantes del aislamiento, la endogamia y la pureza étnica del grupo entero ; de allí la frecuente asimilación entre la endogamia de rango de los « Grandes » y la " pureza étnica » de la comunidad.

El funcionamiento interno de las Casas organiza ciertamente la participación de ciertos individuos en líneas de afiliación genealógica, pero también apunta a mecanizar la transmisión de derechos, bienes y obligaciones. En ambos casos la invocación de pertenencia a una Casa de prestigio constituye un medio de legitimación ideológica de primer orden. Los miembros gozan en primer lugar de un acceso privilegiado a bienes materiales que acentúan sus diferencias « de sangre » respecto del hombre común. La endogamia se traduce en monopolio. Entre los izoceños, las familias de los capitanes han establecido un férreo control de los cargos « tradicionales » (capitanes, chamanes, consejeros) ; pero, también, de las oportunidades económicas que surgen en proyectos estatales o privados de desarrollo, puestos de trabajo como enfermeros o maestros, e incluso como contratistas de la zafra ; por último, hemos constatado también la estrategia clientelística de retribuir con el acceso a estas ventajas económicas a sus seguidores leales. Entre los chané argentinos, si bien se percibe algo de este acceso preferencial a los puestos laborales, existe sin embargo un cierto margen que permanece abierto a una " carrera de talentos ", lo cual permite mayores oportunidades para el surgimiento de nuevos dirigentes. Estas dirigencias alternativas encuentran espacios de poder en las organizaciones de representación supracomunal, los consejos comunitarios o las agrupaciones religiosas, y pueden trabar o no relaciones armónicas con las élites tradicionales.

Las Casas transmiten, sin embargo, bienes de otra naturaleza. Las élites izoceñas heredan $-\mathrm{y}$ disputan - apellidos de prestigio (Iyambae, Barrientos, Sacayande), en torno de los cuales se articulan los linajes. Estos patronímicos han desempeñado un papel crucial en las reivindicaciones del poder político, legitimando a algunos (Iyambae) y cuestionando a otros (Arïgui). Sea como fuere, es evidente que los apellidos destacan a ciertas familias por encima de los comunarios corrientes. De la misma manera, entre los chané argentinos, el apellido Centeno, su familia y los stocks de nombres de la misma se asociaron a lo largo de 
todo el siglo xx con la persistencia del « caciquismo ». La pertenencia a la Casa comporta, por otra parte, la herencia de relaciones sociales « negativas », signadas por la sospecha, la acusación y la venganza. Es el caso del tenaz odio izoceño hacia la memoria de Arïgui, o la voluntad persistente de los líderes chané por desestabilizar la legitimidad de otros capitanes buscando ubicar en su lugar a algún familiar o aliado suyo.

Las Casas aparecen también como custodios o administradores privilegiados de la cultura, la lengua, el espacio y la temporalidad. A primera vista nuestras observaciones parecen coincidir con el testimonio de la literatura etnográfica : la teoría canónica ha definido a los líderes guaraní-hablantes por su inusual capacidad oratoria o cognoscitiva. Sin embargo, la destreza retórica de los líderes chané e izoceños parece ser tan sólo una parte de una lógica de apropiación cultural más amplia, consistente y sistemática. Las Casas preservan una estructura simbólica y cosmológica que comprende ciertamente la lengua, pero también la categorización colectiva del espacio o la propia conciencia histórica. En una palabra, desempeñan la función de auténticas élites intelectuales.

Si bien en grados distintos, entre los izoceños y entre los chané los capitanes y sus familias se presentan como « dueños de la tierra ». No lo hacen sólo en virtud de un cierto manejo "simbólico » de la misma, sino que la misma práctica cotidiana demuestra que el mburuvicha reparte la tierra entre sus comunarios. En el caso del Izozog, la distribución geográfica no parece ser sino un reflejo de la distribución de los diferentes linajes. De igual manera, como hemos visto en los casos de Enrique Iyambae en el Izozog o Mocapoy en el noroeste argentino, con el correr de los años se advierte un desplazamiento de las funciones de los capitanes : de sus antiguas empresas bélicas han pasado a ocuparse de la lucha por las tierras ; una tarea que - como antes la guerra - contribuye a sustentar su legitimidad.

Lo mismo sucede respecto de la conciencia temporal. El atesoramiento de genealogías familiares parece haber articulado la administración colectiva de la memoria y el tiempo. La historia de las comunidades es la historia de las hazañas y desventuras de sus capitanes ${ }^{17}$. Esta estructuración de la memoria grupal en torno de ciertos hitos mnemónicos, relacionados íntimamente con los gobiernos sucesivos de los capitanes y sus actos más significativos, posibilita un estudio de las tradiciones orales con una profundidad temporal impensable en otros grupos étnicos chaqueños. Más allá de que las genealogías puedan haber sido manipuladas, encauzadas, corregidas o aun fraguadas con el correr de los años, lo cierto es que parecen revelar una intención explícita por representar una continuidad diacrónica más o menos lineal ; no es casual, en este sentido, que Lévi-Strauss (1996, p. 145) destacara en la Casa una « voluntad consciente de apertura hacia un devenir histórico ».

Resta analizar cómo se heredan los privilegios jurales de generación en generación. Desgraciadamente la evidencia no permite saber con certeza si las 
siete generaciones de caciques que recuerdan los chané fueron padres e hijos « reales » los unos de los otros. La teoría indica que cada cacique lega su cargo a su hijo mayor, siguiendo la línea agnática. En el Izozog también, existe cierta predilección ideológica por la lógica de la agnación. Pero los datos expuestos permiten dudar de un panorama tan sencillo. La historia entera del Izozog, por ejemplo, muestra cómo la herencia cognática ha sido sistemáticamente manejada, disimulada o invocada según las circunstancias. El caso argentino parece aún más difuso. En dos casos concretos sabemos que los hermanos mayores de los caciques actuales no desempeñan el cargo ; asimismo, la tradición oral menciona otras procedencias o apellidos de los líderes históricos del linaje de Tuyunti, cuya transmisión no coincide con las líneas genealógicas que la mayoría de los informantes suelen declarar en la actualidad. Finalmente, no puede ignorarse el contexto de referencia comparativa que constituye el área cultural del Gran Chaco. Por lo general no hay en ninguno de los grupos chaqueños pautas de descendencia o afiliación demasiado marcadas, y a la tradición de una bilateralidad generalizada se complementa con la vigencia de la uxorilocalidad. En el Izozog, las reglas de residencia se vuelven más flexibles cuando el que se casa es miembro de la Casa « real ». Esta práctica tan frecuente - esta « dialéctica entre la filiación y la residencia » (Lévi-Strauss 1987, p. 146) - impide postular con ligereza cualquier pauta inequívoca y directa de afiliación. Si bien hemos sugerido que el chané común es - por así decirlo - mucho más « chaqueño » que su aristocracia cacical, la afiliación en esta última asume formas complejas, por no decir tortuosas. Más que una línea de descendencia directa, la dinastía cacical parece haberse estructurado en torno de una serie sinuosa, flexible y dúctil de transmisiones cognáticas o indiferenciadas, cuyos criterios variaron de acuerdo con los intereses, los contextos y las coyunturas (ibid., p. 146).

Toda una serie de mecanismos ideológicos, no obstante, permite a los chané representar a posteriori el funcionamiento de las Casas bajo una fachada unilineal. Sea « real » o " clasificatoria » la afiliación a los linajes cacicales, parece evidente que su misma persistencia genealógica revela una forma definida mediante la cual han concebido su propia continuidad : una línea agnática que se remonta hasta el antepasado, José Iyambae en el Izozog, Cochou en Argentina.

No es sólo la descendencia la que se puede manipular, modelar o invertir para legitimar aspiraciones políticas. También es precisa una administración inteligente de los lazos de alianza. Así, en el Izozog encontramos reparticiones de feudos casi medievales entre los hijos del mburuvicha guasu, y lo mismo hicieron los capitanes regionales chané. Los grandes jefes podían casarse, o bien casar a sus hijos, con las hijas de los jefes locales, expandiendo el espectro de sus relaciones afinales para lograr un control político más aceitado. Pero, según los intereses del momento, también podían optar por la estrategia contraria, contrayendo la red de alianza casándose o casando a sus hijos con las respectivas 
ZD, evitando el servicio uxorilocal y reforzando la concentración de fuerza de trabajo, poder político y militar dentro del linaje. Dar o recibir mujeres, endogamia o exogamia, hipergamia o hipogamia parecen, en definitiva, técnicas o estrategias utilizadas de forma alternativa o simultánea para ampliar o cerrar la red matrimonial según las conveniencias.

Otra de las antinomias en las sociedades de « Casas » se da entre el derecho hereditario de sangre y, por otro, la elección o el voto (Lévi-Strauss 1996, p. 144). Se trata de una cuestión candente si tenemos en cuenta el énfasis - a nuestro juicio excesivo - que la literatura ha otorgado a la asamblea en la organización política de los grupos de habla guaraní. En primer lugar; quienes logran mayor persuasión y por ende mayor adhesión en la asamblea - es decir aquellos que « saben » cómo hablar - pertenecen en su enorme mayoría a las familias de prestigio. Las asambleas, más que permitir el surgimiento de nuevos dirigentes, ratifican y tiñen de legitimidad a los «Grandes » de siempre. Un examen de la tumultuosa historia del Izozog permite comprobaciones suplementarias. Una costumbre efectiva de legitimación, sobre todo cuando la sucesión puede originar disputas, es que un líder transmita en vida su cargo a su propio hijo : es lo que hizo Bonifacio Barrientos padre, confirmando ante el pueblo la sucesión en una instancia casi ritual y diluyendo cualquier posibilidad de elección. En el caso argentino, sabemos que después de la muerte del cacique Mayari a nadie se le ocurrió elegir un nuevo jefe, sino que sus hijas desempeñaron las funciones cacicales por algún tiempo hasta que su hermano Taparindu tuvo la edad necesaria para acceder formalmente al liderazgo - que, sólo entonces, fue ratificado por la asamblea comunal. Las asambleas, en suma, parecen haber legitimado más líderes que los que han creado. Más que redistribuir y equilibrar el poder político, parecen haber sido utilizadas para reforzar aún más su concentración en puntos estructurales bien determinados.

En la disputa por la legitimidad, los argumentos no siempre siguen líneas fijas ni carecen de contradicciones e inconsistencias. Cada cual reivindica las armas que convienen, y las defensas y las acusaciones siguen el patrón de las cíclicas antinomias entre tradición/aculturación, antiguos/advenedizos, chané/chiriguano o tapi « guaranizado ». Lo más probable es que la misma acusación que $\mathrm{A}$ dirige a B sea, en pocos años, la que el hijo de B utilice para cuestionar al hijo de A. No es una exageración. La misma acusación de « aculturado » o « mestizo », que en el Izozog fue endilgada a Arïgui, que hoy los miembros del linaje Sacayande desempolvan para cuestionar al actual mburuvicha guasu, o que los chané utilizan para minar la legitimidad de determinados caciques, pudo también ser encauzada a la inversa : el mismo Arïgui utilizó el apoyo de la prefectura provincial para construir una legitimidad erigida sobre títulos oficiales y reconocimientos externos. De igual modo buena parte de la fortaleza actual del linaje Barrientos descansa sobre el monopolio de la administración de las ayudas financieras y las relaciones exteriores. 
Trofeo de los vencedores de la historia, la Casa es una construcción ideológica que fundamenta o legitima una contingencia arbitraria. Manipulando las alcurnias, las estirpes y los linajes, justifica cómo, entre todas las líneas de transmisión, afiliación y herencia - todas igualmente posibles, todas igualmente legítimas algunas triunfan y otras no ; y algunas perduran mientras otras caen en el olvido o aun el oprobio. Pero el hecho de quién « triunfa » es casual. La Casa funciona, justamente, legitimando esta contingencia mediante los lenguajes del parentesco, la consanguinidad y la alianza. El corolario metodológico es que su funcionamiento no puede predecirse con certeza. No se trata de una estructura de linajes, ni una institución de parentesco en sentido estricto, sino más bien de su utilización estratégica, ocasional y hasta caprichosa por parte de los actores sociales.

Si bien destacamos la conciliación de antinomias como apertura y clausura, endogamia y exogamia, tradición y aculturación, patrilinealidad y matrilinealidad, unilinealidad y cognatismo, sería demasiado cómodo afirmar que en cada caso se trata de dos « idiomas » alternativos mediante los cuales las sociedades chané e izoceña han querido representar su propia continuidad. No basta con afirmar, en otras palabras, que existe por un lado el imaginario igualitario y armónico de la gente común, y por el otro los discursos aristocráticos de la estratificación, la endogamia y la jerarquía. Si bien no negamos la coexistencia de ambas lógicas, es preciso destacar que en cada caso sólo uno de los principios ha sido el elegido para representar al grupo ante el exterior. Esta estructura parece formar parte de la identidad más general de estos grupos étnicos. Existe siempre una tensión entre los dos principios que involucra cada antinomia ; pero, también, en todos los casos, ésta se resuelve ideológicamente subordinando a uno de ellos y concediendo una legitimidad mayor al otro, que es el que representa conceptualmente a la totalidad del grupo. En términos de Louis Dumont (1980), se trata de un juego de oposiciones jerárquicas. Las Casas no procuran legitimar; mediante sus contiendas dinásticas, un estado de cosas simétrico ni igualitario. En su actuación detectamos, por el contrario, cierta inclinación por una lógica de la asimetría (Combès y Saignes 1991).

La afiliación concreta a los linajes cacicales chané e izoceños puede ser patrilateral, matrilateral o bilateral, pero la línea agnática es claramente la más prestigiosa. De la misma manera, la exogamia y la endogamia se combinan en permutaciones distintas según los casos, pero la ideología enfatiza una lógica de clausura de los lazos de alianza ; de allí el lenguaje predominante de la « sangre », la « pureza » y la « raza », luego extrapolado a la identidad étnica del grupo. En Argentina, distintos linajes y parcialidades se enfrentan por las jefaturas locales ; pero sólo uno de ellos, el linaje de Tuyunti, ha « representado » a la etnia chané cuando se trata de trabar relaciones con el exterior. Lo mismo sucede entre los izoceños. Una perdurable oposición entre dos zonas geográficas se traduce en términos territoriales (Alto y Bajo Izozog), étnicos (ava-aculturados vs. tapi 
« puros ») y económico-políticos (riqueza corrupta vs. pobreza). El testimonio etnohistórico es claro : cada una de estas dos zonas tiene su propio mburuvicha; pero en todos los casos, cuando se trata de establecer relaciones con el exterior, la totalidad unificada del Izozog es representada por el mburuvicha guasu, que invariablemente pertenece a la zona de río arriba.

Un último punto. Los conflictos y las rivalidades entre los distintos individuos, facciones o linajes no cuestionan el modelo de estratificación jerárquica. Discursos todos de la tradición, la cultura y la pureza étnica que cuestionan al eventual mburuvicha, pero que no hacen más que revalidar la institución de la jefatura. Ni los izoceños discuten la existencia de la ñemunia ete, ni a ningún chané se le pasaría por la cabeza la posibilidad de un mundo sin caciques : sólo se discute quién tiene los argumentos para llenar el casillero.

\section{Palabras finales : CASAS CHANÉ EN « DEMOCRACIA GUARANÍ »}

Si bien hoy persisten las rivalidades entre los linajes izoceños, ha pasado el tiempo ya en que un Bonifacio Barrientos podía decir en voz alta que «la capitanía está en la sangre ». Hacia afuera al menos, el capitán debe ser coherente con otras tendencias que aparecieron en Bolivia en la década de 1980 : el discurso de los movimientos aborígenes, la lucha y los derechos indígenas, discursos acompañados - y nutridos por - un florecimiento sin precedentes de ONG, instituciones de desarrollo, organizaciones « de base », etc..

En 1987 nació, bajo el impulso directo de una ONG católica, la llamada Asamblea del Pueblo Guaraní (APG). El nombre lo dice todo : la organización es una asamblea, que reivindica la visión canónica - y muy democrática - del sistema político « chiriguano »; o mejor dicho, en estas circunstancias, guaraní. Porque la asamblea es guaraní, orgullosamente guaraní. Rechazando el nombre de « chiriguano » por su supuesta etimología despectiva (« castigado por el frío », " estiércol frío ») escamoteó su herencia chané en beneficio exclusivo de sus raíces guaraní - acaso el último episodio en la historia de la " guaranización » de los chiriguano. Hace pocos años, incluso, y valiéndose del prestigio del que goza en Bolivia, la APG incursionó en el noroeste argentino (Hirsch 2003). Sin embargo, se encontró con éxitos desparejos según se enfrentara con comunidades chiriguano, izoceñas o chané. ¿ Cómo ha afectado el discurso - guaraní pero, sobre todo, más democrático - a las viejas aristocracias chané ?

Si hoy los izoceños no se creen " chiriguano », lo cierto es que tampoco se declaran chané : los izoceños « son » guaraní, porque hablan guaraní y porque son miembros, aun con tropezones y muchos problemas, de la APG. El nombre de tapi, recordado por los chiriguano con toda su carga despectiva, es reinterpretado como «los más verdaderos », «los más puros», en suma un nombre "más guaraní », acorde con el gusto del día. 
El panorama es diferente entre los chané del noroeste argentino, que no manifiestan entusiasmo alguno por un discurso que - como los invasores chiriguano antaño - invade sus tierras desde Bolivia. El discurso "guaraní » es indiferente para las comunidades; es, claramente, un discurso chiriguano, un discurso " boliviano ». Empiristas consumados, los chané declaran que los chiriguano son chiriguano, y los chané, chané. Se proclaman más « autóctonos » que los chiriguano, más tradicionalistas, más conservadores de las costumbres, y más argentinos también. Si bien participan algunas veces de las asambleas o talleres organizados por los movimientos indígenas, por lo general rehúsan ser incluidos en las organizaciones « guaraní » de tipo supraétnico.

Existen razones históricas que tal vez puedan explicar esta diferencia. Los chané están presentes en el noroeste argentino al menos desde mediados del siglo XIX ; es decir; llegaron mucho antes que los chiriguano. Los chiriguano aparecieron, décadas después, como advenedizos extranjeros que venían desde el norte primero en incursiones bélicas y luego en busca de trabajo en los ingenios, o huyendo de la guerra del Chaco. Gran parte de la historia oral chané es una sucesión de combates contra los migrantes chiriguano. Los chané no sienten que nada los una con los chiriguano - excepto tal vez un idioma que, en todo caso, tiene también sus diferencias dialectales. Es notable que los chané en Argentina y en el Izozog sigan reclamando no sólo su especificidad cultural sino, también, su superioridad étnica: los primeros rechazando la etiqueta "guaraní », y los segundos proclamando una « superioridad guaraní » sobre los « otros » guaraní.

En el caso de Bolivia, sin embargo, existe un factor de complejidad adicional. Adoptando el discurso de la APG, el Izozog tiene que enfrentarse con otro de sus matices : la « asamblea », la democracia, la representatividad, cosas muy alejadas de capitanías que están « en la sangre » y de una « familia real ». De hecho, bajo la influencia de varias ONG y de una ley democráticamente denominada « de participación popular ", la capitanía izoceña tuvo que adoptar, en 1998, sus estatutos formales. Tres días de discusión fueron necesarios para la redacción de los artículos que regulan la elección del capitán grande ; contra la opinión de Bonifacio Barrientos, y siguiendo los consejos de los técnicos y asesores de ONG, el cargo de mburuvicha guasu ya no es - en el papel al menos - hereditario.

¿ Se trata acaso de un auténtico golpe a la Casa « real» ? No tanto. Primero, porque los estatutos están confinados al papel, una teoría que no va más allá de un borrador que los izoceños comunes ni conocen. Segundo, y más importante, porque el «nuevo » requisito para llegar a ser capitán grande consiste en haber sido anteriormente capitán de comunidad. Esto significa, en la inmensa mayoría de los casos, que el pretendiente pertenece ya a la « familia real » izoceña, y por tanto que el sistema no se vea afectado por las nuevas normas. Conscientes del acaparamiento de cargos por parte de una misma familia, algunos jóvenes izoceños, junto con algunos trabajadores de ONG, han comenzado a pregonar que el anticuado sistema de « la sangre » debe ser reemplazado por criterios como 
los títulos universitarios, la capacidad profesional, la idoneidad, etc. La capitanía no niega de ningún modo esta necesidad ; pero los estudios superiores son caros en Bolivia, e inalcanzables para la mayoría de las familias izoceñas. Los que sí pueden cubrir el costo son aquellos cuyos parientes tienen cargos asalariados en la capitanía, o trabajo remunerado en las ONG : es decir - otra vez - los miembros de los diferentes linajes « reales ». La capitanía, consciente de la necesidad de « capacitación », ha comenzado generosamente a distribuir becas de estudio... entre los jóvenes de « sangre real ».

Así como a partir del siglo XIX el reconocimiento oficial de los capitanes por parte de los blancos se convirtió en un argumento de peso en las luchas internas, el hecho de saber manejar la mecánica « democrática » de las ONG y el Estado constituye una nueva herramienta para la Casa izoceña. Bonifacio es reconocido por los más altos niveles gubernamentales como capitán del Alto y Bajo Izozog ; la reforma agraria de 1996 considera a un único territorio izoceño, al mando de un único capitán. Más todavía : Iyambae, el apellido de la « familia real », se ha convertido en el verdadero slogan del Izozog. Ivi iyambae, literalmente « tierra sin dueño », es el nombre de su territorio ; tví iyambae es el nombre de su oficina en Santa Cruz; iyambae es el pueblo izoceño ; e iyambae son sus dirigentes. Es un lema que, no hace falta decirlo, gusta mucho a las ONG que trabajan en la zona, a las instituciones gubernamentales, a los organismos de apoyo financiero, y a todos aquellos que trabajan con las organizaciones indígenas. Un lema que suena a lucha, en el cual reverberan ecos de libertad. Un lema que, para los propios antropólogos, rememora de algún modo la "tierra sin mal » y la sociedad « contra el Estado » que - dicen - anhelaban los guaraní del siglo xvi. Pero mientras más « sin dueño » se proclaman, y más apoyo se recibe desde fuera, más iya (" dueño ») son los dirigentes de " adentro », donde Iyambae sigue significando "tener sangre ». Iyambae representa a una jerarquía legítima, sí, pero poco "representativa » de sus bases, y no excesivamente democrática (Combès 2003).

Distinta parece ser la situación en el noroeste argentino, aunque es probable que sólo se trate de una simple cuestión de escalas, o aun de tiempo. Tal vez por una mayor facilidad de acceso a los estudios, el chané común puede llegar con más frecuencia a ocupar puestos de importancia local como maestro, enfermero u otras especialidades técnicas. Pero poco o nada más. En los Consejos Comunitarios un porcentaje considerable de los cargos están ocupados por las familias tradicionales de dirigentes. Entre ellas y los pocos dirigentes nuevos que surgen, muchas veces carentes de legitimidad "tradicional », las relaciones no siempre son fáciles.

José es el mburuvicha electo de la comunidad X. Fue electo por hablar bien el castellano. No goza, sin embargo, del prestigio que hemos referido en el caso del linaje tradicional. Una de las actividades predilectas de los chané es el chisme (ndáye). La opinión pública comenta y critica con acidez cada acto, dicho o 
aparición de su mburuvicha. Por ejemplo, organiza buena parte de la venta de artesanías, según afirma para proteger a su gente de las estafas de los intermediarios. Pero esta misma gente lo acusa sin demasiados miramientos de egoísta, de acaparar y no repartir los beneficios de la venta, de no saber hablar en público, de no convocar reuniones. Peor aún: aunque José sea uno de los pocos en la comunidad que recuerdan los mitos y relatos de los antiguos, preocupándose por preservar la lengua y la historia chané, la gran mayoría de la gente fundamenta su antipatía hacia él afirmando que cuando celebran la fiesta del arete, él suele negarse a tocar la flauta con ellos, permaneciendo apartado. Esto se traduce en la acusación infamante de " vergüenza de su propia raza ». Con una expresión tan gráfica como acertada, el propio cacique se queja de que las habladurías lo " deshilachan »; pero no se queda atrás, y califica a su gente de vaga, inútil y desagradecida. Es comprensible que haya intentado renunciar varias veces, sin conseguirlo en ninguna. El inestable equilibrio en que se sostiene su liderato se ve complicado aún más por la presencia de Pedro, su « cacique segundo » y opositor declarado. De hecho, Pedro es uno de los principales animadores del ndáye. Su discurso remite al arakae, la « época de los abuelos », el tiempo de los antepasados, cuando los mburuvicha eran tradicionalistas y temibles guerreros. Por si esto fuera poco, Pedro es pariente cercano del linaje tradicional de capitanes, cuyo apoyo explícito, abierto y público hacia su persona no hace sino desestabilizar todavía más la precaria situación de José.

Más allá de que nadie presente pruebas concluyentes para respaldar las veladas acusaciones, y que a fin de cuentas todo queda en habladurías que pocos están dispuestos a sostener abiertamente, es claro que no es la investidura cacical la que se encuentra en tela de juicio, sino el desempeño personal de José. Pero aunque se cuestione al individuo y no a la institución, es significativo que en reiteradas oportunidades, cuando el cuestionado cacique quiso renunciar, nadie aceptara su decisión. Pensamos que esto se debe a la coyuntura contemporánea. El mburuvicha oficia de mediador entre la comunidad y el mundo ; como corolario, es « responsable » por las relaciones entre ambas esferas. Agente de cambio pero a la vez dependiente de la legitimación tradicional, el cacique queda atrapado en una posición ambivalente. La comunidad deposita su destino en manos de un líder no muy convencido de enfrentar tamaña tarea. Cualquier desgracia le es imputada de inmediato; y los éxitos y las bonanzas, que también se le atribuyen, últimamente resultan algo escasos. El imaginario colectivo subraya con insistencia implacable la oposición entre los poderosos caciques de antaño y sus pobres sucesores. José se encuentra en la posición de chivo expiatorio, y no precisamente en el (más honorable) sentido frazeriano.

Es evidente que el ndáye es crítico, pero lo es en términos de un sistema de valores y representaciones compartidos, con respecto a los cuales se mide y contrasta la conducta del cacique (Villar 2001). Lo que apunta de nuevo al soporte ideológico de la investidura cacical. Es claro que José no cuenta con la 
misma legitimación « sincrónica » de la que puede servirse el cacique de Tuyunti, basada sobre el alcance excepcional de su red de parentesco y alianzas matrimoniales ; tampoco goza de la legitimación « diacrónica » que le podría otorgar un prestigioso linaje dinástico. Frente a las genealogías de Taparindu, no puede sino aparecer como un advenedizo. Sin embargo, lo curioso es que José deba apelar a estos mismos argumentos, y que deba expresar su defensa en términos de parentesco si quiere lograr una legitimidad que al menos por el momento le ha resultado esquiva. También afirma que su propio abuelo viajó en busca de las tierras con el mítico Mocapoy ; pero, sin embargo, la historia « oficial » del linaje principal es sesgada, y por ello no lo reconoce. De la misma forma, sostiene que heredó su cargo de su hermano, y éste a su vez de sus padres y sus abuelos; es decir; que también traza su ascendencia en forma de linaje, y se presenta como un descendiente de caciques. Esto es discutido por el resto de la gente. La defensa y su refutación muestran que las disputas políticas se traducen una vez más al lenguaje del parentesco, y que de éste al plano de la identidad étnica no hay sino un paso. La acusación de "vergüenza de la raza » aparece, entonces, bajo una nueva luz. Los enemigos de José explican que, en última instancia, su falta de legitimidad se debe a que es "cruzadito"; y a las genealogías que invoca, replican lo que todos saben : que su familia viene de una comunidad chiriguano en la frontera con Bolivia, localidad donde algunos pocos chané conviven «entreverados» con una mayoría muy aculturada de chiriguano. José paga culpas que, en definitiva, se resumen en una desgracia : ser " menos » chané.

Una vez más se detecta un discurso étnico - chané en un caso, « guaraní » en el otro -, un discurso político, un tejido de chismes, acusaciones y habladurías, una trama de parentescos reales, acomodados o inventados. Los chané argentinos mantienen buena parte del sistema « aristocrático » observado por Nordenskiöld ; y los « Grandes » izoceños adquieren, cada vez más, una maestría sin par en el juego democrático externo para reforzar internamente su tradicional dominio político. Qué duda cabe : si no se trata de una monarquía, como lo quería Giannecchini, al menos sí parece una oligarquía. Con nuevos avatares y argumentos inéditos, las Casas chané parecen tener largos días por delante, y seguirán alimentando muchos años más los ndáye y arakae miari sin los cuales perderían mucho de su sabor y de su legitimidad. *

* Manuscrit reçu en janvier 2004, accepté pour publication en novembre 2004.

NOTAS

1. Agradecemos a Pablo Sendon, Isabelle Daillant y Philippe Erikson por su ayuda y sugerencias, así como también a los comentaristas anónimos del Journal de la Société des Américanistes. 
2. En la actualidad, el clivaje parece expresarse en la afiliación del cacique y el resto del pueblo a distintos partidos politicos.

3. Nordenskiöld $(2002$, p. 212) escribe « varias veces he escuchado a algunos indios vanagloriándose de sus relaciones de parentesco con la nobleza ». Incluso anota que detectó algún que otro engaño en las genealogías : « un chané afirmaba ser descendiente del gran Hinu Parava, lo que parece que no es cierto » (ibid., p. 213). Casi un siglo más tarde, en una entrevista que le realizó un diario local, un joven aspirante a cacique chané se presentó con su nombre en castellano y un doble apellido formado por el suyo y, por supuesto, el de la familia cacical.

4. A falta de alianzas matrimoniales, pueden establecerse otros vínculos con la « realeza ", por ejemplo a través de las relaciones de compadrazgo.

5. Nordenskiöld (2002, p. 213) afirmaba que los linajes cacicales poseían objetos antiguos que no podian encontrarse en las otras familias.

6. Hay noticias, por ejemplo, de prácticas de poligamia por parte de los big men, selecionando esposas que eran hermanas o madres e hijas entre sí (Giannecchini 1996, pp. 299-300).

7. Para la importancia de los términos avunculares en la organización sociopolítica chiriguano, ver Braunstein (1983). Puede advertirse también su importancia específica en los saludos y en los cantos de cortejo documentados por Giannecchini (1996, pp. 295, 322 y 361$)$.

8. Podría pensarse además que el matrimonio avuncular fortalece la ideología de los grupos cacicales en un sentido ulterior. Si, de acuerdo con la costumbre de las élites, un líder hace casar a su hijo con la ZD de éste, el niño resultante será su « nieto » (SS) y a la vez su « bisnieto » (DDS), un lazo doble que bien puede reforzar las ideas de la consanguinidad, la endogamia y la continuidad familiar.

9. José Manuel Iyambae consiguió de la prefectura de Santa Cruz un título oficial de « Capitán Grande » en 1854 (MHSC 2/53 10-10-1854); murió, todavía en el cargo, en la década de 1890.

10. Su abuela (FM) es hija de Casimiro Iyambae (hijo del antepasado José Iyambae), pero criada por su tío Sacayande (FB) y considerada su hija (ver figura 2).

11. Bonifacio es por asi decirlo un Barrientos " clasificatorio ». Pertenece " de sangre " al linaje Arïgui, ascendencia que sus opositores sacan oportunamente a relucir cuando les conviene.

12. El Alto Izozog estaba muy poco poblado por los tapi antes de finales del siglo XIx. La comunidad de Tamané, ubicada hoy en la frontera entre el Bajo y el extremo Bajo Izozog, era considerada en 1862 como el punto " más central » de la zona (MHSC 2/69 4-VI-1862).

13. El Izozog quedó prácticamente aislado durante toda la época colonial, $y$ las fuentes son escasas en este periodo. En cuanto a la memoria oral, se pasa directamente de Kaa Poti y su hijo - el " primer » Iyambae - a los mburuvicha del siglo XIX, en una suerte de cortocircuito genealógico (Combès s.d.).

14. En la perspectiva de estos izoceños, Casiano, al apoyar a los bolivianos, estaba apoyando a los blancos ; por el contrario, los paraguayos - de habla guaraní también - no eran considerados como karai.

15. Enrique mató accidentalmente a su esposa. Algunos dicen que huyó para escapar de la justicia karai, que buscaba pretextos para removerlo ; otros alegan que no se trató de un accidente, y que huyó para evitar la justicia izoceña. Las versiones cambian según el vínculo que el narrador tenga con el propio Enrique.

16. Este matrimonio tal vez sea el primer ejemplo de legitimación del poder de los capitanes mediante uniones con la familia real izoceña. El Alto está dominado por ava ; pero estos mismos ava necesitan, para volver su dominio aceptable, consolidar sus lazos con la dinastia tapi, reeditando de algún modo aquel proceso mediante el cual los guaraní lograron dominar a los chané ocupando el lugar más alto de su jerarquía interna.

17. En el Izozog se acusa a Uchuapi de haber dejado entrar a los blancos a mediados del siglo XIX. Su contraparte argentina es un capitán chané acusado de haber permitido la instalación de una planta petrolera. Verdaderos " agentes " históricos del devenir de su pueblo, los " grandes hombres » son siempre los responsables de las fortunas y las desgracias (Villar 2001, p. 96). 


\section{BIBLIOGRAFÍA}

Siglas de Archivos

ANB : Archivo Nacional de Bolivia, Sucre

MI : $\quad$ Ministerio del Interior

IZO : Documentos de la capitanía del Alto y Bajo Izozog (la numeración fue puesta arbitrariamente por nosotros).

IZO-1 : Título ejecutorial de Yovi y Aguaraigua, 1945

IZO-3 : Título ejecutorial de Ibasiriri y Güirayoasa, 1948

IZO-9 : Título ejecutorial de Copere e Yapiroa, 1949

IZO-14 : Credencial otorgado por la subprefectura de Cordillera a Bonifacio Barrientos Iyambae, 9-VI-1953.

MHSC : Archivo prefectural de Santa Cruz, Bolivia (Museo Histórico de Santa Cruz)

Albó Xavier

1990 Los Guarani-Chiriguanos 3. La comunidad hoy, CIPCA, La Paz.

Braunstein José

1983 "Algunos rasgos de la organización social de los indígenas del Gran Chaco ", Trabajos de Etnología, 2, Buenos Aires.

Campana Domenico del

1902 "Notizie intorno ai chiriguani », Archivio per l'Antropologia e la etnologia, XXXII, Società italiana d'antropologia, etnologia e psicologia comparata, Florencia.

CARdús José

1886 Las misiones franciscanas entre los infieles de Bolivia. Descripción del estado de ellas en 1883 y 1884, Librería de la Inmaculada Concepción, Barcelona.

CARSten Janet y Stephen Hugh-Jones, eds

1995 About the House : Lévi-Strauss and beyond, Cambridge University Press, Cambridge.

Clastres Pierre

1974 La Société contre l'État, Éditions de Minuit, Paris.

Combès Isabelle

2003 " $i$ Con o sin dueños ? Participación política y "democracia indígena" en el Chaco boliviano ", seminario Participación politica, democracia y movimientos indigenas en los Andes, Embajada de Francia/IFEA/PIEB, 2-XII-2003, La Paz.

s.d. Etno-historias del Izozog [en preparación].

Combès Isabelle, ed.

1999 Arakae. Historia de las comunidades izoceñas, CABI/WCS Bolivia/Kaa-Iya, Santa Cruz. 
COMBÈs Isabelle y Kathleen LowreY

2004 «Slaves without Masters? Arawakan Dynasties Among the Chiriguano » [en prensa en The Journal of Ethnohistory].

Comisès Isabelle y Thierry SAIGNES

1991 Alter Ego. Naissance de l'identité chiriguano, EHESS/Cahiers de l'Homme, Paris

DAMES y MOORE (Empresa consultora)

2001 Al este de los Andes, al sur del Amazonas. Descubrimientos arqueológicos en los bosques secos de los llanos de Bolivia, Gas TransBoliviano, Santa Cruz.

DUMONT Louis

1980 Homo hierarchicus. The Caste System and Its Implications, Chicago University Press, Chicago.

Giannecchini Doroteo

1996 Historia natural, etnografia, geografia, lingüistica del Chaco boliviano, FIS/Centro Eclesial de Documentación, Tarija [1898].

HiRsch Silvia

1991 Political organization among the Izoceño Indians of Bolivia, tesis doctoral, University of California, Los Angeles.

2003 « The emergence of political organizations among the Guaraní Indians of Bolivia and Argentina : a comparative perspective ", in E. Langer y E. Muñoz, eds, Contemporary Indigenous Movements in Latin America, Scholarly Resources Inc., Washington, pp. 81-101.

HORNBORG Alf

1988 Dualism and hierarchy in Lowland South America. Trajectories of indigenous social Organization, Almqvist \& Wiksell, Stockholm.

Hugh-Jones Stephen

1993 «Clear descent or ambiguous houses? A re-examination of Tukanoan social organisation ", L'Homme, XXXIII (126-128), pp. 65-120.

Lévi-Strauss Claude

1984 Paroles Données, Plon, Paris, pp. 189-191.

1987 La Vía de las máscaras, Siglo Veintiuno, Madrid.

1996 "Casa », in P. Bonte y M. Izard, eds, Diccionario de etnología y antropología, Akal, Madrid, pp. 144-145.

Lowrey Kathleen

2003 Enchanted ecology : magic, science and nature in the Bolivian Chaco, Ph. D. dissertation, University of Chicago, Chicago.

Matienzo Juan de

1918 "Carta a S. M. », in Roberto Leviller, ed., La Audiencia de Charcas. Correspondencia de presidentes y oidores, tomo 1, pp. 54-60, Colección de publicaciones históricas de la biblioteca del Congreso argentino, Madrid [1561].

Métraux Alfred

1948 "Tribes of the Eastern Slopes of the Bolivian Andes. Chiriguano and Chané ", in J. Steward, ed., Handbook of South American Indians, III, Smithsonian Institution, Washington. 
Nino Bernardino de

1912 Etnografia chiriguana, Tipografia Comercial de Ismael Argote, La Paz.

NORDENSKIÖLD Erland

2002 La vida de los indios. El Gran Chaco (Sudamérica), APCOB/Plural, La Paz [1912].

RIESTER Jürgen

1998 Yembosingaro guasu, el Gran Fumar. Literatura sagrada y profana guaraní, APCOB, Santa Cruz [5 tomos].

\section{SAIGNES Thierry}

1985 «La Guerre contre l'histoire. Les Chiriguano du Xvi ${ }^{\mathrm{e}}$ au $\mathrm{XIX}^{\mathrm{e}}$ siècle », Journal de la Société des Américanistes, 71, pp. 175-190.

1990 Ava y Karai : Ensayos sobre la frontera chiriguano (Siglos XvI-Xx), HISBOL, La Paz.

Santos Granero Fernando

2002 "The Arawakan matrix : ethos, language and history in native South America ", in Jonathan Hill y Fernando Santos Granero, eds, Comparative Arawakan histories. Rethinking languages family and cultural area in Amazonia, University of Illinois Press, Urbana.

SUSNIK Branislava

1968 Chiriguanos I. Dimensiones etnosociales, Museo etnográfico Andrés Barbero, Asunción.

1971 El indio colonial del Paraguay III-1. El Chaqueño: Guaycurúes y ChanesArawak, Museo etnográfico Andrés Barbero, Asunción.

1983 Los aborigenes del Paraguay V. Ciclo vital y estructura social, Museo etnográfico Andrés Barbero, Asunción.

Thouar Arthur

1997 A través del Gran Chaco, 1883-1887, Los Amigos del Libro, La Paz/Cochabamba [1887].

VILLAR Diego

2001 "Sobre el ndáye entre los chané», Scripta Ethnologica, 22, pp. 93-102, Buenos Aires.

VILLAR Diego y Federico Bossert

2004 "La onomástica chané en clave etnográfica y comparativa », Acta Americana, 12 (1), pp. 49-78, Uppsala. 